\title{
Neutronic Assessment of Transmutation Target Compositions in Heterogeneous Sodium Fast Reactor Geometries
}

S. Bays

M. Pope

B. Forget

R. Ferrer

February 2008

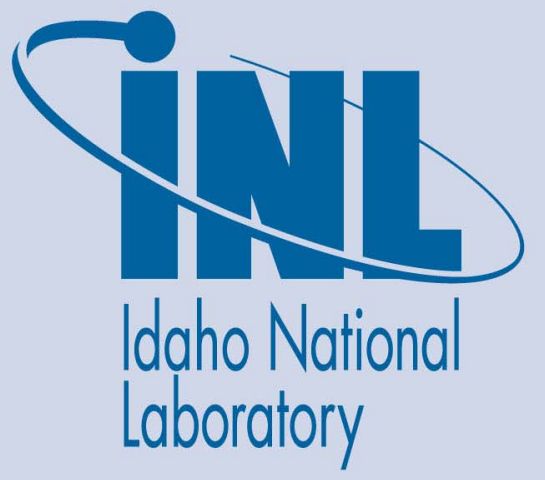

The INL is a U.S. Department of Energy National Laboratory operated by Battelle Energy Alliance 
INL/EXT-07-13643

Rev. 1

\section{Neutronic Assessment of Transmutation Target Compositions in Heterogeneous Sodium Fast Reactor Geometries}
S. Bays
M. Pope
B. Forget
R. Ferrer

February 2008

Idaho National Laboratory
Idaho Falls, Idaho 83415

Prepared for the

U.S. Department of Energy

Office of Nuclear Energy

Under DOE Idaho Operations Office

Contract DE-AC07-05ID14517 
Neutronic Assessment of Transmutation Target Compositions in Heterogeneous Sodium Fast Reactor Geometries

INL/EXT-07-13643

February 2008

Approved by

Samuel Bays, Principal Author

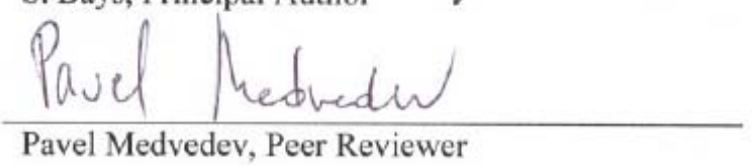

$\frac{2-18-2008}{\text { Date }}$
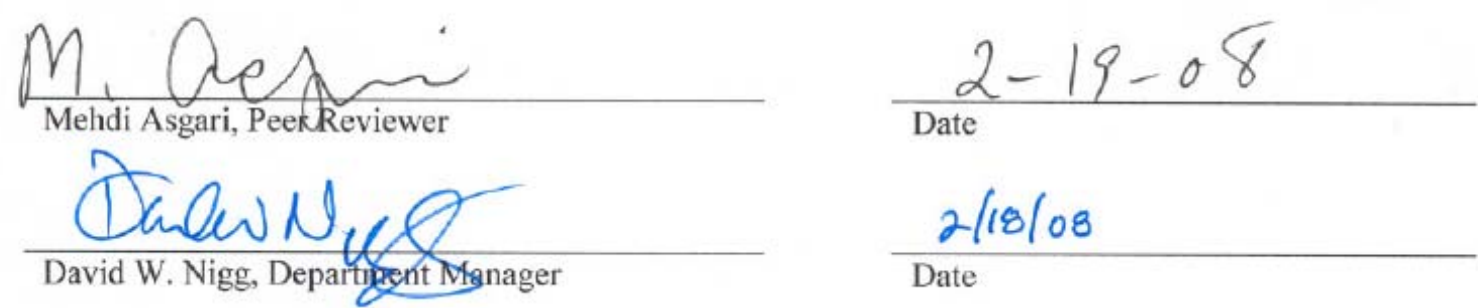


\section{Executive Summary}

The sodium fast reactor is under consideration for consuming the transuranic waste in the spent nuclear fuel generated by light water reactors. This work is concerned with specialized target assemblies for an oxide-fueled sodium fast reactor that are designed exclusively for burning the americium and higher mass actinide component of light water reactor spent nuclear fuel (SNF). The associated gamma and neutron radioactivity, as well as thermal heat, associated with decay of these actinides may significantly complicate fuel handling and fabrication of recycled fast reactor fuel. The objective of using targets is to isolate in a smaller number of assemblies these concentrations of higher actinides, thus reducing the volume of fuel having more rigorous handling requirements or a more complicated fabrication process. This is in contrast to homogeneous recycle where all recycled actinides are distributed among all fuel assemblies. Several heterogeneous core geometries were evaluated to determine the fewest target assemblies required to burn these actinides without violating a set of established fuel performance criteria. The DIF3D/REBUS code from Argonne National Laboratory was used to perform the core physics and accompanying fuel cycle calculations in support of this work. Using the REBUS code, each core design was evaluated at the equilibrium cycle condition.

These studies were performed using the Advanced Burner Reactor as the reference core and assembly design. In the reference homogeneous core, all transuranics are recovered and returned to the driver fuel assemblies. Alternatively, in the heterogeneous cases $\mathrm{Np}+\mathrm{Pu}$ was recovered and returned to driver fuel while $\mathrm{Am}+\mathrm{Cm}+\mathrm{Bk}+\mathrm{Cf}$ was recovered and put into the target assemblies. An external supply of transuranics having a SNF isotopic vector was added to the recovered material after each cycle to compensate for transuranics destroyed by fission. In order to give a fair comparison between the heterogeneous target cases and the homogeneous reference case, the ratio of $\mathrm{Am}+\mathrm{Cm}+\mathrm{Bk}+\mathrm{Cf}$ to $\mathrm{Np}+\mathrm{Pu}$ in the external supply of transuranics was held constant and equal to the actual ratio found in SNF. Because this ratio was always respected in conjunction with a constant thermal power rating and a relatively invariant conversion ratio, the external makeup feed rate of each isotope was also relatively invariant throughout this study. Therefore, an equal comparison could be made between the reference homogeneous core and all heterogeneous designs.

For this initial study, the same assembly design used by the driver fuel was adopted for the transmutation target assemblies. Also investigated was the effect of using uranium oxide (UOX) versus fertile-free magnesium oxide $(\mathrm{MgO})$ as the carrying matrix for the transmutation target composition.

Four core geometries with target assemblies were evaluated in this study, ranging from a 6-target case having one target assembly at each corner of the hexagonal core, to a 48-target case where the entire first row of radial reflectors are replaced by target assemblies. The neutronics analysis of these core designs was repeated for both UOX and MgO target matrix materials. Several limits were adopted by which to evaluate the merits of each target arrangement. First, all driver and target assemblies in the core were restricted to a fast fluence limit of $4 \times 10^{23} \mathrm{~cm}^{-2}(\mathrm{E}>0.1 \mathrm{MeV})$. The plenum pressure in the driver and target fuel pins was not allowed to exceed $100 \mathrm{~atm}$. The temperature of the inner cladding wall was not allowed to exceed $650^{\circ} \mathrm{C}$ to prevent or minimize the possibility of fuel-to-cladding chemical interaction. Finally, all assemblies were limited to pellet centerline temperatures equal to or less than those of the homogeneous reference Advanced Burner Reactor (ABR). It is likely that decay heat and radioactivity limits place constraints on the target's minor actinide enrichment with respect to manufacturability and transportability issues. These limits are not well known at this time and are not considered here. Also, the melting temperatures of some of the compositions considered here for targets are not well known and, thus, are ignored in this study. 
These preliminary studies indicate that, because of the low neutron flux and power density in targets, due to their location in the outer region of the core, the transmutation targets' thermal limits are not likely to be challenged for the core geometries evaluated here. The helium production, and corresponding gas plenum pressures, was found to be the limiting parameter in determining the fresh fuel minor actinide concentration of the targets. Based on these studies, this limiting parameter required the transuranic concentration in the targets be limited to less than approximately 35 volume percent. In this work, this corresponded to having at least 18 target assemblies (UOX or $\mathrm{MgO}$ matrix) in the first row of reflector. This 18 -target core geometry and composition gave a power rating in the targets of $3.5 \mathrm{~kW} / \mathrm{m}$. This is the approximate upper end of the scale of power ratings evaluated by this study. Separating curium after each recycle of the targets gave a slight decrease in helium generation during the irradiation by avoiding the introduction of $\mathrm{Cm}-244$ in the fresh target assembly. However, this option ultimately leads to net curium generation as a byproduct of the fuel cycle. Inclusion of curium leads to a curium equilibrium concentration in the fresh targets being approximately 30 weight percent of the minor actinides with the remaining $70 \mathrm{w} / \mathrm{o}$ being americium. By replacing the entire first row of the radial reflector with 48 target assemblies, the equilibrium transuranic target concentration could be reduced to approximately 10 volume percent. The 48-target core geometry with an $\mathrm{MgO}$ target matrix gives a power rating in the targets of $1.5 \mathrm{~kW} / \mathrm{m}$. This is the approximate lower end of the scale of power ratings evaluated by this study. The reduction in transuranic loading reduced the target plenum pressure at the end of the target life to less than that of the driver fuel. With regard to the selection of a UOX or MgO transmutation target matrix, it was found that the effect of plutonium breeding in a uranium-based target matrix does not significantly change the core's overall transuranic burning performance unless many target assemblies are used. This was the case when 48 targets having a UOX matrix were used. The large uranium and low transuranic concentration in this target scenario caused significant plutonium breeding which increased the core conversion ratio. Furthermore, using a UOX matrix rather than the inert $\mathrm{MgO}$ matrix did not have a significant impact on the minor actinide burning efficiency of the targets. 


\section{DISCLAIMER}

This report was prepared as an account of work sponsored by an agency of the United States Government. Neither the United States Government nor any agency thereof, or any of their employees, makes any warranty, express or implied, or assumes any legal liability or responsibility for the accuracy, completeness, or usefulness of any information, apparatus, product, or process disclosed, or represents that its use would not infringe privately owned rights. Reference herein to any specific commercial product, process, or service by trade name, trademark, manufacturer, or otherwise, does not necessarily constitute or imply its enforcement, recommendation, or favoring by the United States Government or any agency thereof. The views and opinions of authors expressed herein do not necessarily state or reflect those of the United States Government or any agency thereof. 


\section{ACKNOWLEDGEMENTS}

The authors would like to thank Jon Carmack and Mitchell Meyer for their technical feedback and discussions. Douglas Porter and Steven Hayes are appreciated for lending their experience on sodium fast reactor fuel design.

Many thanks are given to Bevin Brush and Thomas Johnson for their tour of fuel handling and separations operations at the EBR-II fuel cycle facility. Special thanks are given to Steven Piet for his technical insight into the system dynamics of closing the domestic and international fuel cycle. Many thanks are given to Pavel Medvedev for his input on establishing the fuel performance criteria used in this report. 


\section{CONTENTS}

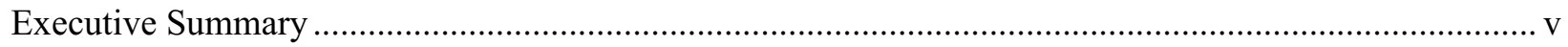

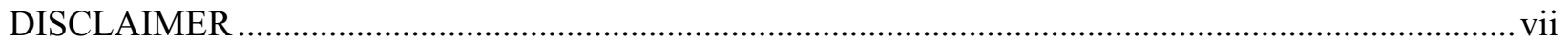

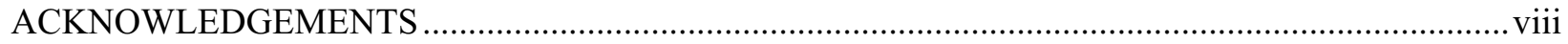

GLOSSARY, ACRONYMS, AND ABBREVIATIONS …...............................................................

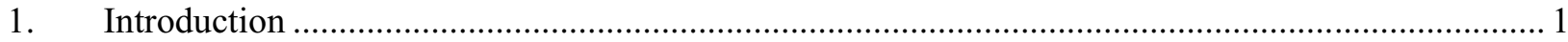

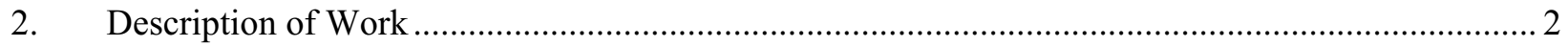

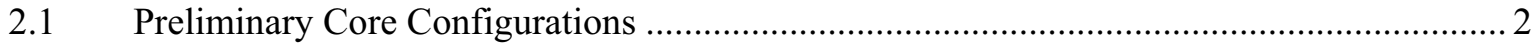

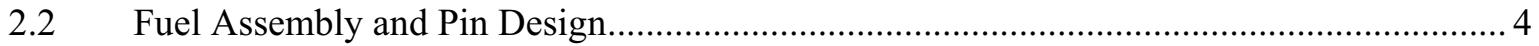

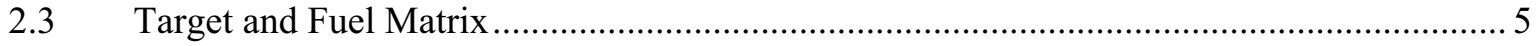

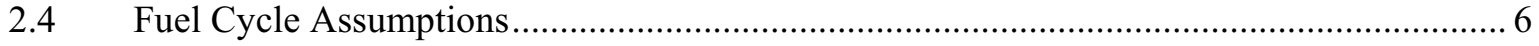

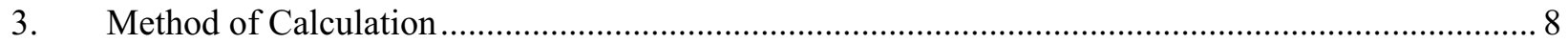

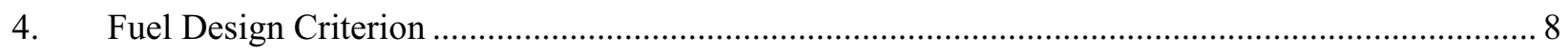

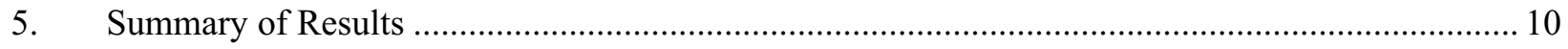

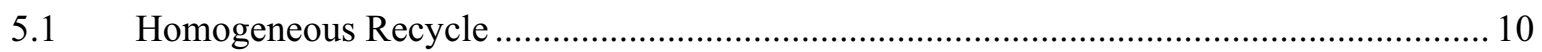

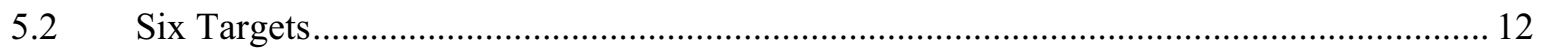

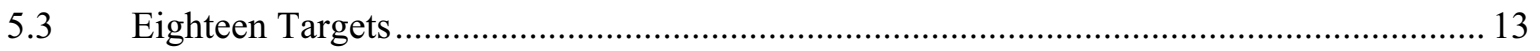

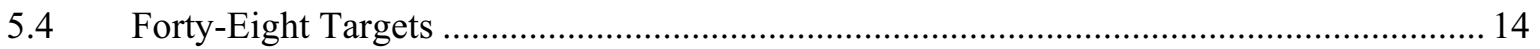

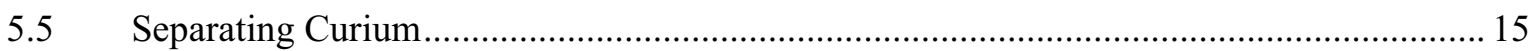

5.6 Magnesium Oxide and Uranium Oxide Matrix .............................................................. 18

5.7 Composition Range of Analyzed Heterogeneous Designs ............................................... 22

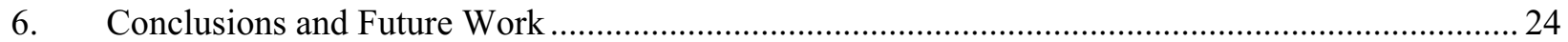

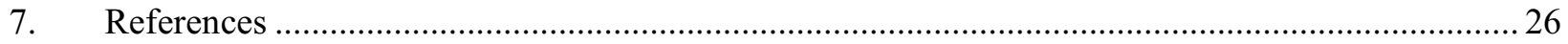

\section{FIGURES}

1. Radial heterogeneous sodium fast reactor core designs ........................................................ 3

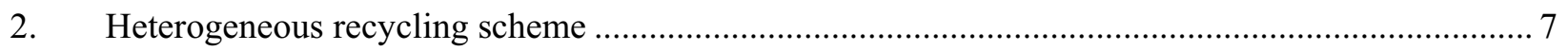


3. Axial temperature distributions for the hottest fuel rod.

4. Partial pressure contributions to the total plenum pressure for an average ABR fuel pin............... 12

5. Percent helium gas contributions by parent isotope for the UOX-18f case (Cm retained) ............. 16

6. Percent helium gas contributions by parent isotope for the UOX-18f-Am case (Cm discarded)..... 16

7. Buildup and depletion of transmutation target isotopes in UOX-18f (Cm retained).................... 17

8. Buildup and depletion of transmutation target isotopes in UOX-18f-Am (Cm discarded)............. 17

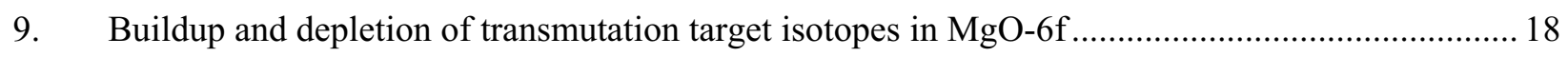

10. Buildup and depletion of transmutation target isotopes in UOX-18f ........................................ 19

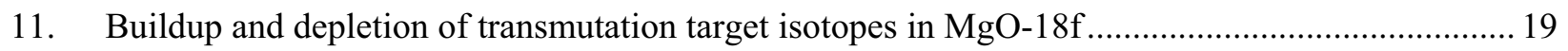

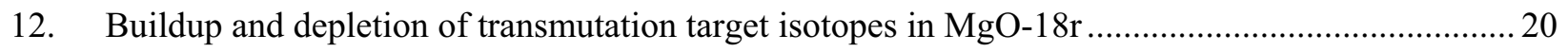

13. Buildup and depletion of transmutation target isotopes in UOX-48 …........................................ 20

14. Buildup and depletion of transmutation target isotopes in $\mathrm{MgO}-48$........................................... 21

\section{TABLES}

1. Description of the radial heterogeneous core designs .............................................................. 2

2. Isotopic vectors defining external "makeup" supply of transuranic material (in mass fraction)....... 4

3. Pin and assembly design (Identical for Driver Fuel and Transmutation Target)............................ 5

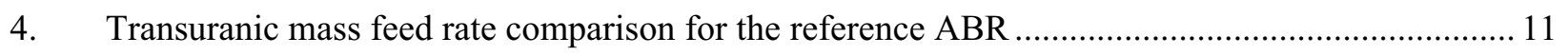

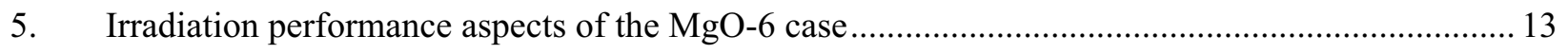

6. Irradiation performance aspects of RH-SFR cases with 18 transmutation targets ........................ 14

7. Helium and fission product gas partial pressures (in atm) in the fuel pin plenum .......................... 14

8. Irradiation performance aspects of of RH-SFR cases with 48 transmutation targets ...................... 15

9. Irradiation performance aspects of RH-SFR transmutation targets with and without curium ......... 16

10. General elemental composition (w/o) of the transmutation targets' transuranic component ...........22

11. General isotopic composition (w/o) of the transmutation targets' transuranic component ..............22 


\section{GLOSSARY, ACRONYMS, AND ABBREVIATIONS}

\begin{tabular}{|c|c|}
\hline $\mathrm{ABR}$ & Advanced Burner Reactor \\
\hline atm & atmosphere \\
\hline $\mathrm{BOEC}$ & Beginning of Equilibrium Cycle \\
\hline $\mathrm{CR}$ & Conversion Ratio \\
\hline dpa & Displacements per Atom \\
\hline EBR-II & Experimental Breeder Reactor - II \\
\hline EFPD & Effective Full Power Day \\
\hline $\mathrm{E}_{\mathrm{MA}}$ & Minor Actinide Destruction Efficiency \\
\hline EOEC & End of Equilibrium Cycle \\
\hline $\mathrm{E}_{\mathrm{TRU}}$ & Transuranic Destruction Efficiency \\
\hline FCCI & Fuel-to-Cladding Chemical Interaction \\
\hline FCMI & Fuel-to-Cladding Mechanical Interaction \\
\hline FFTF & Fast Flux Test Facility \\
\hline LHGR & Linear Heat Generation Rate \\
\hline LWR & Light Water Reactor \\
\hline MOX & Mixed Oxide Fuel \\
\hline MWY & megawatt year \\
\hline PWR & Pressurized Water Reactor \\
\hline RGU & Reactor Grade Uranium \\
\hline RH-SFR & Radial Heterogeneous - Sodium Fast Reactor \\
\hline SFR & Sodium Fast Reactor \\
\hline SNF & Spent Nuclear Fuel \\
\hline SPIN & Séparation-Incineration Program \\
\hline S-PRISM & Super - Power Reactor Innovative Small Module \\
\hline UOX & Uranium Oxide \\
\hline
\end{tabular}




\section{Introduction}

Sodium Fast Reactors (SFRs) are currently being evaluated as a means of eliminating the long-lived transuranic isotopes produced by Light Water Reactors (LWR). The fast spectrum of a SFR typically has flux levels that are an order of magnitude greater than those typical of thermal reactors. Historically, the surplus neutron flux generated by the SFR has been used to breed new fissile material by targeting the capture reaction of U-238, which transmutes into Pu-239. In the context of a transuranicburning SFR, these excess neutrons are applied to destroying, by fission, the transuranic atoms of Spent Nuclear Fuel (SNF) produced by LWRs.

The amount of actinide mass destroyed in a SFR is directly proportional to the amount of energy produced by fission in the fuel. For a plutonium "breeding" SFR operating in an equilibrium fuel cycle, most of the actinide mass undergoing fission is $\mathrm{Pu}-239$. However, $\mathrm{Pu}-239$ begins as a U-238 atom at an earlier stage in the irradiation or fuel cycle. Since the breeder SFR consumes uranium and not plutonium as the only external supply of mass, it could be considered a burner reactor of uranium. A SFR can be operated in a plutonium or transuranic "burning" mode by decreasing the amount of U-238 in the fuel, thus lowering the conversion ratio (CR). Trans-uranium isotopes are formed by neutron capture (i.e., without fission) in uranium. Hence, removing uranium from the fuel prevents the formation of trans-uranium isotopes. However, it does not guarantee that all transuranic isotopes will fission with the same efficiency. Higher mass actinides, such as curium, berkelium and californium, are produced in a SNF transuranic-burning reactor more readily than a breeder reactor fueled on a uranium and $\mathrm{Pu}-239$ rich fuel vector. The higher mass actinides are produced because of the fertile americium concentration of LWR SNF [1]. Much of the SNF americium mass is not fissile, but rather has a relatively sharply resolved energy threshold for fission. Therefore, successive neutron captures must occur before the fertile americium transmutes into a fissile atom. In the process, higher mass actinides are formed.

The fast spectrum provides some neutrons at energies above this fission threshold for all of the actinide isotopes, including fertile U-238 and the minor actinides Np-237 and Am-241. These isotopes have an even neutron number, which gives them longer half lives compared to the odd-neutron isotopes of their respective elements. The even number of neutrons also tends to cause these isotopes to have a threshold for fission on the order of $1 \mathrm{MeV}$. It is this capacity to fission any actinide at some extent, that stops the accumulation of higher mass actinides, in the traditional breeder SFR. This was because the transmutation precursors to these elements, $\mathrm{Pu}-241, \mathrm{Pu}-242$ and Am-243, were sufficiently destroyed by fission as they were created. Therefore, isotopes heavier than Pu-241 never accumulated in the SFR's fuel cycle. (e.g., no accumulation of the parent Pu-241 for the beta decay formation of Am-241) However, this is not the case for LWR fuels. In the thermal spectrum of an LWR, the ratio of fission-to-capture reactions is less than the fast spectrum for fissile isotopes and extremely low for fertile isotopes. Therefore, $\mathrm{Am}-241$ accumulates as a decay daughter of $\mathrm{Pu}-241$. Also, $\mathrm{Pu}-242$ is formed from neutron capture in $\mathrm{Pu}-241$. This fertile $\mathrm{Pu}-242$ isotope can go on to capture yet another neutron to form short-lived $\mathrm{Pu}-243$, which subsequently beta decays into Am-243. Am-243 can also be formed from the successive neutron bombardment, without fission, of Am-241. The formation of americium, Am-243 in particular, is a transmutation gateway for producing the higher mass actinides. When the precursor isotopes are introduced to the SFR in the form of the LWR plutonium vector, this curium gateway is already opened at the beginning of the irradiation. Because the LWR grade plutonium is introduced every cycle, the higher mass actinides build to an equilibrium concentration in the fuel cycle. However, because of the higher fission-to-absorption ratios, this equilibrium concentration is qualitatively less than multi-recycling in a thermal spectrum. 
It is important to minimize the production of americium and the higher mass actinides from a fuel fabrication perspective. Americium oxide, like its metal form, is more volatile than uranium and plutonium oxides. The hazard americium handling creates for a worker is due to the potential inhalation dose from the Am-241 alpha activity. Higher mass actinides also have associated gamma and neutron radiation fields, further complicating the fuel fabrication operations. Cf-252, for example, produces spontaneous fission neutrons on the order of $10^{15} \mathrm{n} / \mathrm{s}$ per $\mathrm{kg}$.

It may be impossible to completely prevent the production of americium and the higher mass actinides due to the nature of the LWR SNF plutonium vector. However, it is possible to quarantine the americium and higher mass actinides into a special transmutation target designed to minimize fuel handling/fabrication operations with this material [2]. The discussion of these heterogeneous target options is the focus of this report.

\section{Description of Work}

Several heterogeneous SFR geometries were considered in this work. The selection of the transmutation matrix was also considered as a design variable. Currently, a matrix phase of uranium oxide (UOX) or magnesium oxide $(\mathrm{MgO})$ is considered to contain the (Am, Cm, Bk, Cf) $\mathrm{O}_{2}$ or $\mathrm{MA}-\mathrm{O}_{2}$ phase. The selection of macro- versus micro-dispersion fuels is outside the scope of this discussion. This is because the heterogeneous effect of the $\mathrm{MA}-\mathrm{O}_{2}$ kernel within the target pellet is not expected to have a significant neutronic influence on the core due to the long mean free path of fast neutrons. In fact, for most SFR calculations, including these, the heterogeneity of the fuel rod within the assembly does not have a significant reactivity influence. Thus, the driver fuel and transmutation target composition for each pin is homogenized with the sodium coolant and cladding material across each fuel assembly.

\subsection{Preliminary Core Configurations}

Eight core designs (and/or their associated fuel cycle options) were considered in the following Radial Heterogeneous - Sodium Fast Reactor (RH-SFR) comparative analysis. These cases are listed in Table 1. All cases are compared with a reference homogenous core with a homogeneous recycling strategy. This homogeneous reference was taken to be the oxide-fueled Advanced Burner Reactor (ABR) with a CR of 0.75 taken from Hoffman et al. in ANL-AFCI-177 [3]. For nomenclature clarification, homogeneous recycling implies lumped separation of all transuranic isotopes.

Table 1. Description of the radial heterogeneous core designs.

\begin{tabular}{|c|c|c|c|c|}
\hline Case Name & Driver Assemblies & Target Assemblies & Description & Matrix \\
\hline UOX-18f-Am & 132 & 18 & Separate and Store Curium & UOX \\
\hline UOX-18f & 132 & 18 & Keep Curium in Fuel Cycle & UOX \\
\hline UOX-48 & 144 & 48 & Replace Radial Reflector & UOX \\
\hline MgO-6 & 144 & 6 & Located in Six Corners & $\mathrm{MgO}$ \\
\hline $\mathrm{MgO}-18 \mathrm{f}$ & 132 & 18 & Displaced Outer Core Fuel & $\mathrm{MgO}$ \\
\hline $\mathrm{MgO}-18 \mathrm{r}$ & 144 & 18 & Displaced Radial Reflector & $\mathrm{MgO}$ \\
\hline $\mathrm{MgO}-48$ & 144 & 48 & Replace Radial Reflector & $\mathrm{MgO}$ \\
\hline $\mathrm{ABR}$ & 144 & 0 & MA Located in Driver Fuel & $\mathrm{n} / \mathrm{a}$ \\
\hline
\end{tabular}

These core design options are shown in Figure 1. Two possible bounding cases are investigated. The reasonable maximum number of targets that can be wrapped around the driver core is investigated in the UOX-48 and MgO-48 cases where the entire first row of reflectors is replaced with target assemblies. The absolute minimum number of targets, at nearly $100 \% \mathrm{MA}-\mathrm{O}_{2}$, content is investigated in the MgO- 6 case. The UOX-18f and MgO- $18 \mathrm{f}$ cases investigate the potential gain in transmutation efficiency by 
moving 12 of the 18 targets into the active core (i.e., driver fuel locations). The $\mathrm{MgO}-18 \mathrm{r}$ case investigates the transmutation efficiency if these targets remain outside of the core, and, hence, do not displace driver fuel. Finally, the transmutation and fuel performance tradeoff of multi-recycling curium in the targets, versus discarding curium after ever cycle, is investigated in the UOX-18f-Am case.
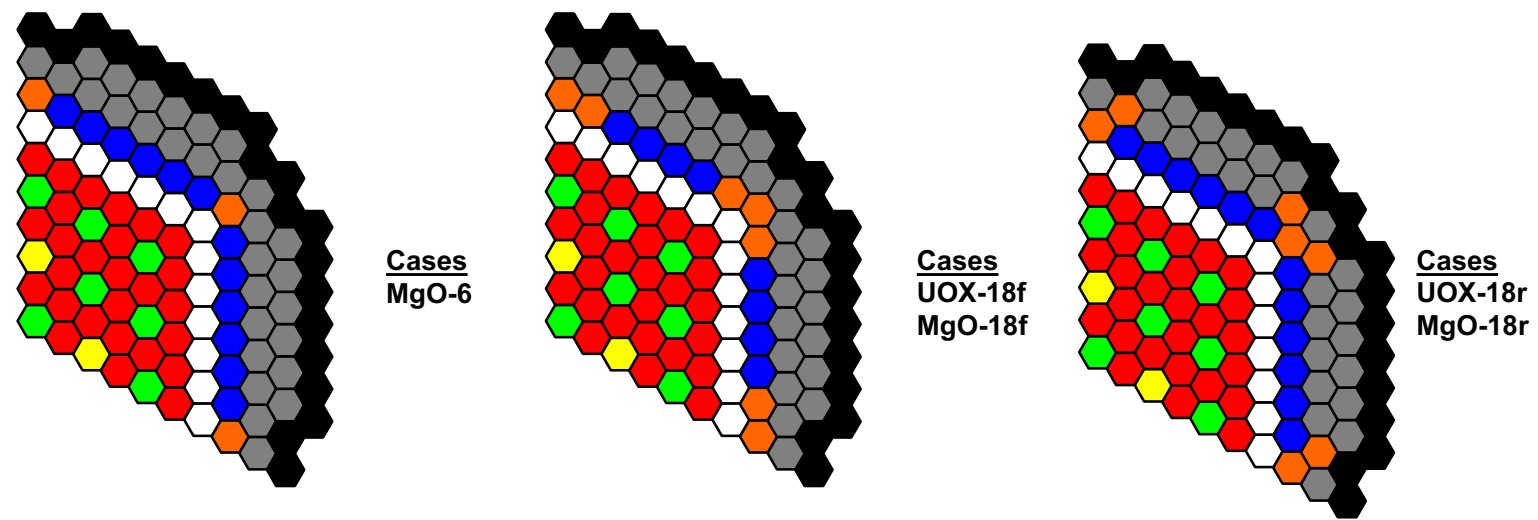
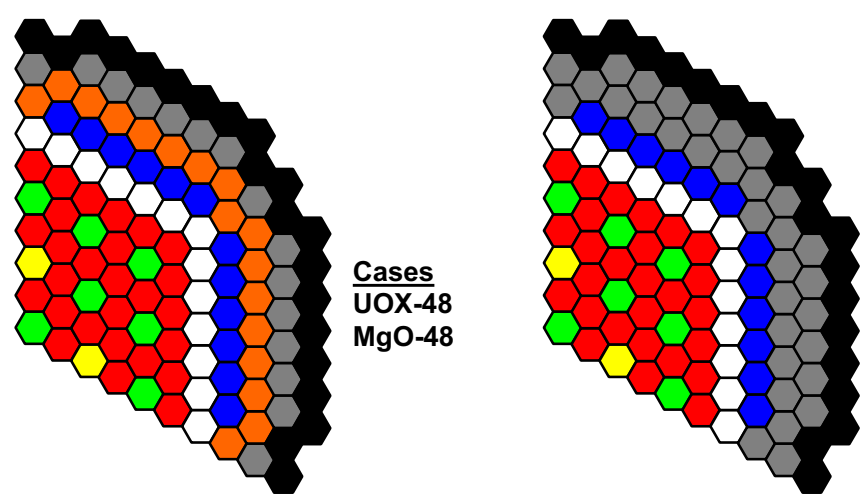

Cases

Advanced Burner Reactor $(\mathrm{CR}=0.75)$ with Oxide Fuel
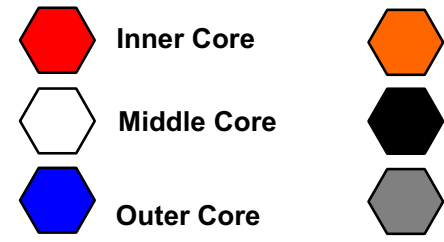

MA Targets

Shield

Reflector

Figure 1. Radial heterogeneous sodium fast reactor core designs.

Because the CR is roughly constant in all cases, the external supply of transuranic material remained approximately constant and equivalent to the homogeneous reference. Therefore, the feed rate of each isotope per fission energy produced is approximately constant. Because the final calculated cycle length varies for each design, the quantity of fresh fuel and target transuranic charged per cycle is allowed to vary. However, since the thermal power rating of each core design is the same (1000 MWth) and the CR is approximately constant, the rate of externally supplied (or makeup) transuranic feed per Effective Full Power Day (EFPD) of operation is made approximately constant.

The isotopic vector of the external transuranic supply is derived from a pressurized water reactor (PWR) SNF with a burnup of $50 \mathrm{MWD} / \mathrm{kg}$ cooled for five years before reprocessing. An additional two years cooling time, post reprocessing, is applied to account for fabrication and transportation time to the SFR. This feed vector was tabulated for a repeating PWR fuel assembly lattice calculation using the coupled NEWT/TRITON depletion code component of the SCALE5.1 code package [4]. The feed vectors for the homogeneous reference and heterogeneous core designs are given in mass fraction in 
Table 2. Note that the radial heterogeneous driver fuel and transmutation target isotopic vectors have been renormalized to $100 \%$ for each composition. However, for every $1 \mathrm{~kg}$ of $\mathrm{Np}+\mathrm{Pu}$ supplied to the driver fuel, there is $0.06257 \mathrm{~kg}$ of $\mathrm{Am}+\mathrm{Cm}+\mathrm{Bk}+\mathrm{Cf}$ supplied to the transmutation targets. This is also the approximate ratio of $\mathrm{Am}+\mathrm{Cm}+\mathrm{Bk}+\mathrm{Cf}$ to $\mathrm{Np}+\mathrm{Pu}$ in the homogeneous reference case. Note that the driver fuel is not completely free of americium, because $\mathrm{Pu}-241$ has been allowed to decay into Am-241 during the two year holding time following reprocessing.

Table 2. Isotopic vectors defining external "makeup" supply of transuranic material (in mass fraction).

\begin{tabular}{|c|c|c|c|}
\hline & $\begin{array}{c}\text { Homogeneous } \\
\text { Reference Driver }\end{array}$ & $\begin{array}{c}\text { Radial } \\
\text { Heterogeneous } \\
\text { Driver }\end{array}$ & $\begin{array}{c}\text { Radial } \\
\text { Heterogeneous } \\
\text { Target }\end{array}$ \\
\hline $\mathrm{U}-234$ & $3.9240 \mathrm{E}-04$ & $4.1690 \mathrm{E}-04$ & $2.4140 \mathrm{E}-07$ \\
\hline $\mathrm{U}-235$ & $2.6086 \mathrm{E}-05$ & $2.7720 \mathrm{E}-05$ & $2.9010 \mathrm{E}-09$ \\
\hline $\mathrm{U}-236$ & $4.6998 \mathrm{E}-05$ & $4.9890 \mathrm{E}-05$ & $8.2980 \mathrm{E}-07$ \\
\hline $\mathrm{Np}-237$ & $2.5563 \mathrm{E}-07$ & $2.7160 \mathrm{E}-07$ & $5.7010 \mathrm{E}-12$ \\
\hline Pu-238 & $5.5393 \mathrm{E}-02$ & $5.8750 \mathrm{E}-02$ & $1.7550 \mathrm{E}-03$ \\
\hline Pu-239 & $2.5048 \mathrm{E}-02$ & $2.6610 \mathrm{E}-02$ & $2.5530 \mathrm{E}-05$ \\
\hline Pu-240 & $4.6129 \mathrm{E}-01$ & $4.9010 \mathrm{E}-01$ & $1.0230 \mathrm{E}-04$ \\
\hline Pu-241 & $2.2642 \mathrm{E}-01$ & $2.4010 \mathrm{E}-01$ & $7.8880 \mathrm{E}-03$ \\
\hline Pu-242 & $9.3565 \mathrm{E}-02$ & $9.9420 \mathrm{E}-02$ & $9.9060 \mathrm{E}-07$ \\
\hline $\mathrm{Am}-241$ & $7.0039 \mathrm{E}-02$ & $7.4420 \mathrm{E}-02$ & $3.1200 \mathrm{E}-06$ \\
\hline $\mathrm{Am}-242 \mathrm{~m}$ & $4.2200 \mathrm{E}-02$ & $1.0060 \mathrm{E}-02$ & $5.5570 \mathrm{E}-01$ \\
\hline $\mathrm{Am}-243$ & $9.9716 \mathrm{E}-05$ & $0.0000 \mathrm{E}+00$ & $1.6940 \mathrm{E}-03$ \\
\hline $\mathrm{Cm}-242$ & $1.9067 \mathrm{E}-02$ & $0.0000 \mathrm{E}+00$ & $3.2380 \mathrm{E}-01$ \\
\hline $\mathrm{Cm}-243$ & $2.9415 \mathrm{E}-07$ & $0.0000 \mathrm{E}+00$ & $4.9960 \mathrm{E}-06$ \\
\hline $\mathrm{Cm}-244$ & $5.1334 \mathrm{E}-05$ & $0.0000 \mathrm{E}+00$ & $8.7190 \mathrm{E}-04$ \\
\hline $\mathrm{Cm}-245$ & $5.9322 \mathrm{E}-03$ & $0.0000 \mathrm{E}+00$ & $1.0080 \mathrm{E}-01$ \\
\hline $\mathrm{Cm}-246$ & $3.8126 \mathrm{E}-04$ & $0.0000 \mathrm{E}+00$ & $6.4750 \mathrm{E}-03$ \\
\hline $\mathrm{Cm}-247$ & $4.9266 \mathrm{E}-05$ & $0.0000 \mathrm{E}+00$ & $8.3670 \mathrm{E}-04$ \\
\hline $\mathrm{Cm}-248$ & $7.7651 \mathrm{E}-07$ & $0.0000 \mathrm{E}+00$ & $1.3190 \mathrm{E}-05$ \\
\hline $\mathrm{Cf}-249$ & $5.6439 \mathrm{E}-08$ & $0.0000 \mathrm{E}+00$ & $9.5860 \mathrm{E}-07$ \\
\hline $\mathrm{Cf}-250$ & $7.8112 \mathrm{E}-10$ & $0.0000 \mathrm{E}+00$ & $1.3270 \mathrm{E}-08$ \\
\hline $\mathrm{Cf}-251$ & $2.3026 \mathrm{E}-10$ & $0.0000 \mathrm{E}+00$ & $3.9110 \mathrm{E}-09$ \\
\hline $\mathrm{Cf}-252$ & $1.3431 \mathrm{E}-10$ & $0.0000 \mathrm{E}+00$ & $2.2810 \mathrm{E}-09$ \\
\hline & $1.4700 \mathrm{E}-11$ & $0.0000 \mathrm{E}+00$ & $2.4970 \mathrm{E}-10$ \\
\hline & & & \\
\hline
\end{tabular}

Another fixed parameter of this comparative analysis is the fuel pin and assembly design which were the same in each case. Significant modifications to the fuel pin diameter can considerably change the core CR. In fact, this is how previous studies modulated the CR of the ABR in his parametric analyses. The sensitivity of CR on fuel pin diameter is related to the driver fuel enrichment. For equal transuranic loading, a reduction in uranium loading is achieved by decreasing the pin diameter. Hence, the transuranic enrichment is increased. The equilibrium transuranic enrichment of the heterogeneous driver cores considered in this report is determined by only the cycle length. As will be discussed in a later section, the cycle length was optimized for each case to reach a maximum fast neutron fluence limit in the fuel cladding and hexagonal duct.

\subsection{Fuel Assembly and Pin Design}

Both the driver fuel and transmutation target assemblies have the same assembly and pin dimensions as the oxide-fueled ABR $\mathrm{CR}=0.75$ case investigated by Hoffman. This assembly design is similar to the driver fuel of the Super-Power Reactor Innovative Small Module (S-PRISM) design proposed by General Electric [5]. The assembly consists of 271 pins encapsulated in a hexagonal shroud 
or duct. A flow orifice at the duct inlet regulates the coolant uptake through the assembly. Using the flow orifices, coolant can be increased for the hottest fuel and decreased for the coldest fuel such that the coolant exit temperature across the core is relatively constant [6]. However, for the following thermal analyses, the effect of the flow orifice is neglected. Therefore, the flow orifice is a mechanism to create fuel performance margin above and beyond this preliminary evaluation of target strategies.

The dimensions of the fuel pins and assembly are given in Table 3. All dimensions used in this analysis are for cold un-irradiated fuel.

Table 3. Pin and assembly design (Identical for Driver Fuel and Transmutation Target).

\begin{tabular}{|c|c|}
\hline Fuel Type & Oxide \\
\hline Approximate core conversion ratio & 0.75 \\
\hline Assembly pitch, cm & 16.142 \\
\hline Inter-assembly gap, cm & 0.432 \\
\hline Duct outside flat-to-flat, cm & 15.710 \\
\hline Duct material & $\mathrm{HT}-9$ \\
\hline Duct thickness, cm & 0.394 \\
\hline Pins per assembly & 271 \\
\hline Spacer type & Wire wrap \\
\hline Bond material in gap & $\mathrm{He}$ \\
\hline Plenum height, cm & 170.82 \\
\hline Core height, cm & 137.16 \\
\hline Axial reflector height, cm & 114.30 \\
\hline Overall pin length, cm & 422.28 \\
\hline Fuel smeared/ fabrication density, \% TD & $85 / 89.4$ \\
\hline Pin outer diameter, cm & 0.808 \\
\hline Cladding thickness, cm & 0.0635 \\
\hline Spacer wire wrap diameter, cm & 0.0797 \\
\hline Pin pitch-to-diameter ratio & 1.099 \\
\hline
\end{tabular}

The core radial power density is tailored by employing a split enrichment approach. The middle and outer core region, shown in Figure 1, have enrichments 1.25 and 1.5 times greater than the inner core region, respectively. This increases the reactivity worth of these outer enrichment zones. The additional reactivity is intended to overcome the drag on core power, in these regions, caused by radial leakage. With the enrichment splitting, the radial power profile in the inner and middle core regions is fairly constant. However, volumetric power density falls off sharply in the outer enrichment zone in the outermost row of fuel. Because the power density in this outer region is less than the inner regions, a longer irradiation time is necessary to achieve the same burnup. Therefore, inner and middle core fuel assemblies are irradiated for six cycles, whereas the outer core is irradiated for seven cycles. The target assemblies being placed, for the most part, on the outer edge of the driver core, can be irradiated to 10 cycles before the materials limitations of the fuel, cladding and structures are met.

\subsection{Target and Fuel Matrix}

Two transmutation matrix types are considered here: UOX and $\mathrm{MgO}$. Uranium Oxide is considered due to the irradiation performance database established for SFR Mixed Oxide Fuels (MOX), which is the current composition choice for the RH-SFR driver fuel. Minor actinide carrying UOX targets were irradiated in the Phénix reactor during the 1980's during the SUPERFACT experiments of the Séparation-Incineration (SPIN) program [7]. This program irradiated low (2\%) and high (20\%) enrichments of $\mathrm{AmO}_{2}$ and $\mathrm{NpO}_{2}$ in a UOX matrix. The general consensus established by these tests was: (1) overall transuranic destruction was diminished by plutonium production from the uranium, motivating 
consideration of a fertile free "inert" matrix, and (2) an optimum inert matrix should have a solution to swelling and deformation caused by the helium created by the $\mathrm{Cm}-242$ alpha particle decay.

Magnesium Oxide is an inert matrix that has been evaluated by several international programs for applications in SFRs. The thermal, epithermal, and fast spectrum cross sections for magnesium isotopes are all at least an order of magnitude less than that for the main non-fuel components of iron, chromium, or sodium. This attribute gives $\mathrm{MgO}$ high neutron transparency even in the fast spectrum. $\mathrm{MgO}$ irradiations performed in the Phénix reactor during the 1990's during the MATINA experiment showed some swelling of $\mathrm{MgO}$ after irradiation to a fast fluence of $1.95 \times 10^{22} \mathrm{~cm}^{-2}(\mathrm{E}>0.1 \mathrm{MeV})$ [8]. However, this swelling did not lead to any pellet interaction with the cladding. Magnesium Oxide also has a high thermal conductivity but has been reported to lose $50 \%$ of its initial thermal conductivity after being exposed to a fast fluence of only $1.0 \times 10^{22} \mathrm{~cm}^{-2}$ [7]. However, $\mathrm{MgO}$ exhibits order of magnitude higher thermal conductivities than UOX for temperatures below $1200 \mathrm{~K}$ [9]. Therefore, $\mathrm{MgO}$ may exhibit excellent thermal performance if irradiated in a low power region of the core, such as the outer radial periphery or reflector region. $\mathrm{MgO}$ is selected as a reference material to study the transmutation performance of inert matrix targets in the RH-SFR because of its high neutron transparency and an adequate irradiation database.

\subsection{Fuel Cycle Assumptions}

The separation and recycling strategy investigated here assumes the ability to partition uranium, $\mathrm{Np}+\mathrm{Pu}$, and $\mathrm{Am}+\mathrm{Cm}+\mathrm{Bk}+\mathrm{Cf}$ into three separate waste streams. The separation strategy is outlined in Figure 2. The general philosophy of maintaining the $\mathrm{Am}+\mathrm{Cm}+\mathrm{Bk}+\mathrm{Cf}$ inventory in transmutation targets is indicated by the hot-cell and glove-box images at the center of the figure. In each recycle, the $\mathrm{Np}+\mathrm{Pu}$ isotopes, formed by transmutation and subsequent decay, is separated from the unburned americium and higher mass actinides in the targets. The unburned $\mathrm{Np}+\mathrm{Pu}$ and uranium in the spent SFR driver fuel is then recycled and blended with the $\mathrm{Np}+\mathrm{Pu}$ mass in the spent transmutation target along with the external makeup feed. The driver external makeup feed is comprised of SNF $\mathrm{Np}+\mathrm{Pu}$ and uranium, i.e., reactor grade uranium $(\mathrm{RGU})$. The unburned $\mathrm{Am}+\mathrm{Cm}+\mathrm{Bk}+\mathrm{Cf}$ mass at discharge is recycled and blended with the $\mathrm{Am}+\mathrm{Cm}+\mathrm{Bk}+\mathrm{Cf}$ generated in the driver fuel along with the transmutation target external makeup feed. The transmutation target external makeup feed is the $\mathrm{Am}+\mathrm{Cm}+\mathrm{Bk}+\mathrm{Cf}$ corresponding to the SNF used to create the external $\mathrm{Np}+\mathrm{Pu}$ feed at the LWR SNF separations plant.

The assumption is made that, for homogeneous recycling, with all higher mass actinides recycled into the driver fuel, a transuranic concentration or fuel enrichment could be reached that would require more radiological protection to fuel handlers than feasibly accomplished in a glove box environment. This scenario is assumed to require the construction of a hot-cell. The size and cost of hot-cell infrastructure is assumed to be roughly determined by the mass throughput of fuel. At this point, it becomes economic to separate americium and higher mass actinides and use the hot-cell for only this small fraction of the overall transuranic mass in the fuel cycle. One of the principle advantages of this heterogeneous recycle approach is that, after blending with uranium, the fresh driver fuel is kept relatively free from the high gamma and neutron radiation fields. It is, therefore, presumed that a glove box process could be used for fabricating the majority of the fuel, as is shown in Figure 2.

The targets are irradiated on a multi-batch basis. As opposed to "once-through-then-out" strategies, a fraction of the targets are removed and replaced with fresh targets every cycle. This ensures that only reprocessing losses of transuranics are sent to geologic disposal, which can be encapsulated in glass or other waste forms. Since, the ratio of $\mathrm{Np}+\mathrm{Pu}$ to $\mathrm{Am}+\mathrm{Cm}+\mathrm{Bk}+\mathrm{Cf}$ in the transuranic mass feed rate is always respected, the amount of minor actinide throughput through the core is approximately constant for each heterogeneous design. Because of this relationship, what must change as an indication of transmutation performance is the amount of mass throughput of the hot-cell component of the fuel 
cycle. Therefore, the transmutation performance of each design can be considered by simply evaluating how many transmutation targets per driver fuel assembly are charged to the core every cycle (i.e., the fuel fabricated in the hot-cell).

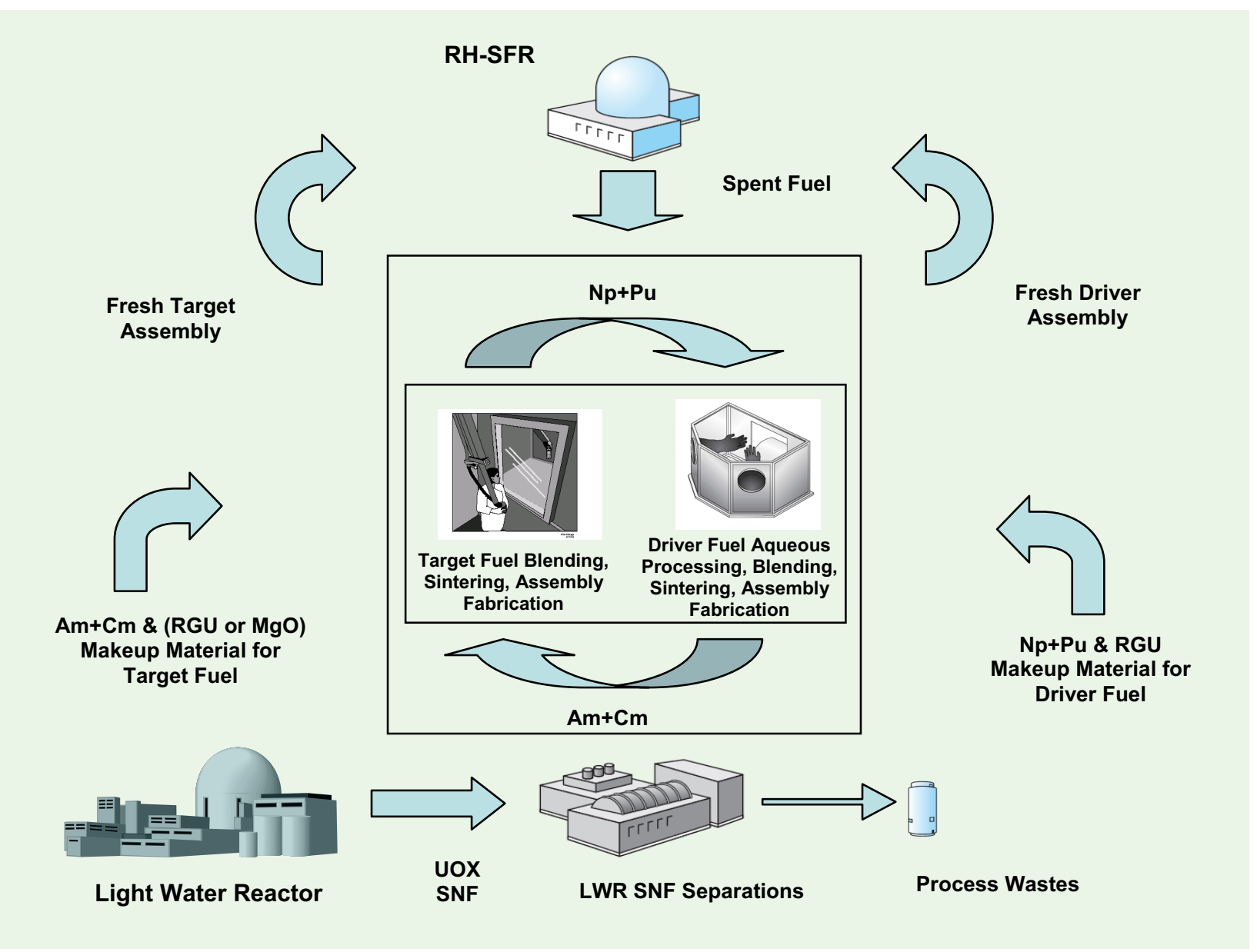

Figure 2. Heterogeneous recycling scheme.

However, judging transmutation performance simply on the number of transmutation targets per driver fuel is not sufficient to determine the effectiveness of any given core design or transmutation target composition. This is because one would simply need to calculate the volume of pure $\mathrm{MA}-\mathrm{O}_{2}$ fed to the core per cycle and convert that volume into the minimum number of corresponding target assemblies. This case will be addressed in a following section. There are other design factors affecting in-pile performance that reflects the realistic number of targets sent to the core. A set of design criteria is laid out in Section 4 that establishes a working envelope for quantifying the expected fuel and reactor performance behavior of these conceptual designs. Transmutation performance can be judged based on the minor actinide enrichment in the targets at beginning of life. The minor actinide enrichment is taken to be the volume fraction of the transuranic component over the matrix component in the transmutation target. When comparing two core designs with the equal number of target assemblies, the tie can be broken by the design with the smallest enrichment. A smaller enrichment is caused by less material recovered through recycling from the previous cycle. 


\section{Method of Calculation}

The Argonne National Lab fast reactor codes MC2-2, DIF3D and REBUS are used for the reactor physics and fuel cycle calculations [10]. The MC2-2 code was used to generate a 33 group cross section set for each driver fuel enrichment zone, the targets, reflectors, and shields. Starting with an ultra-fine group ENDF-V/B cross section library, MC2-2 creates a collapsed cross section set by performing a zero dimensional infinite dilution critical buckling search using the extended P1 method [11]. This zerodimensional approach does not account for spatial shielding effects between the various core regions. However, for fast reactor calculations, it is generally sufficient due to the long neutron mean free path. The fast flux is almost entirely in the unresolved resonance range, thus making unresolved energy shielding and the unresolved resonance treatment the dominating effects in the group collapsing. MC2-2 also performs a resolved resonance broadening treatment at user-defined material and fuel temperatures. These cross sections are then used in a criticality calculation performed by DIF3D.

The DIF3D diffusion code was used to solve the multi-group steady state neutron diffusion equation using a hexagonal-z nodal coordinate system [12]. In the nodal discretization, each hexagonal node in the lateral direction represents an assembly. Because the mean free path is on the dimensional level of a fuel assembly, the coolant, fuel and structural materials are homogenized across each assembly.

REBUS uses DIF3D to perform a criticality search for the uncontrolled excess reactivity at each time step in its fuel depletion algorithm. In this search, the fresh driver fuel transuranic enrichment is adjusted until enough beginning of equilibrium-cycle (BOEC) excess reactivity exists to keep the core critical until the end of equilibrium-cycle (EOEC). Once the criticality search is completed, the fluxes from DIF3D are used in an exponential matrix algorithm to carry out the fuel depletion, transmutation, and decay of the fuel (or target) isotopic vector within each time step. This algorithm assumes that regional fluxes do not change significantly over this time step. REBUS performs the in-core fuel management and out-of-core cooling, reprocessing, and re-fabricating for each reactor cycle. These operations are carried out until the BOEC excess reactivity is found for the prescribed cycle length.

REBUS was not initially designed to optimize this cycle length as a function of the peak fluence. Instead, a peak burnup specification is provided which allows the user to define the maximum discharge burnup of any given batch of fuel in the reactor. However, given the fact that the cladding and structural steel limit on fast fluence is frequently the limiting factor in the fuel irradiation, peak burnup was not used to constrain the RH-SFR's cycle length. Instead, a series of FORTRAN codes were written to automatically read neutron flux data from the REBUS output and predict the cycle length required to obtain the maximum fluence limit. A corrector-predictor routine is applied which updates the cycle length used by REBUS and repeats the equilibrium cycle calculation until the user-specified fluence limit is observed over the entire core.

\section{Fuel Design Criterion}

A set of fuel design criteria for the RH-SFR was established to ensure that the heterogeneous core design does not produce peak power levels in the driver fuel and transmutation targets that could cause the fuel to fail. First, the power in the hottest fuel pins should be less than that necessary to melt the fuel.

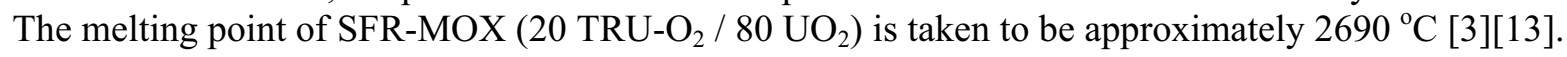
The melting point of MA- $\mathrm{O}_{2}$ in mixtures of $\mathrm{UOX}$ or $\mathrm{MgO}$ is not well known. Therefore, the RH-SFR transmutation target and driver fuel centerline temperatures are compared to the peak fuel temperature of the ABR (SFR-MOX) reference case.

Secondly, the cladding inner wall temperature must be less than that necessary to cause fuel-to-cladding chemical interaction (FCCI) or eutectic melting between the fuel and cladding. FCCI 
begins when uranium, plutonium and fission product lanthanide metals inter-diffuse with the iron in the cladding [14]. This inter-diffusion forms a low melting point phase of these constituents [15]. If the temperature shared between the fuel and cladding inner wall exceeds the melting temperature of this newly formed phase, eutectic melting of the cladding begins. Eutectic liquefaction is a cladding wastage phenomenon that was common during metal fuel irradiations conducted at the Experimental Breeder Reactor (EBR)-II. Pahl et al. described the results of FCCI tests, performed at EBR-II, as an "interdiffusion of lanthanides in the fuel and cladding constituents leading to formation of brittle layers in the cladding wall that were prone to failure[16]." Pahl did not observe FCCI interactions for temperatures below $650{ }^{\circ} \mathrm{C}$.

Lahm et al. discusses the erosion of the EBR-II Mark II cladding as a result of this FCCI interdiffusion [17]. As the fuel slug swelled and came into contact with the cladding, the contact pressure led to creep damage and possible stress rupture later in life. Once the contact is made, FCCI occurs, allowing iron in the cladding to be traded with lanthanide metals in the fuel. Lahm et al. found that this newly formed uranium-iron phase had a eutectic solidus temperature below the melting point of the cladding. If the fuel was operated at temperatures above this eutectic temperature, a liquid interface between cladding and fuel would form, accelerating the FCCI diffusion. The diffusion feedback causes the cladding to thin and lose its strength as iron in the cladding is consumed by the liquid interface. This cladding wastage serves to increase the frequency of stress rupture in the driver fuel.

A peak fast fluence limit of $4.0 \times 10^{23} \mathrm{~cm}^{-2}(\mathrm{E}>0.1 \mathrm{MeV})$ was adopted as the maximum allowable cladding exposure for the RH-SFR cladding and structure components. This criterion is based on the irradiation experience gained at the Fast Flux Test Facillity (FFTF), using the fast reactor grade steel, HT-9 [18]. HT-9 is a feritic/martensitic steel with a 12 w/o chromium content. HT-9 qualification at FFTF and the Experimental EBR-II showed no elongation or cladding breach after being irradiated up to $3.9 \times 10^{23} \mathrm{~cm}^{-2}$. Depending on the hardness of the neutron spectrum, this fluence roughly corresponds to a cladding damage rate of 200 displacements per atom (dpa). HT-9 has been proposed for the S-PRISM's and ABR's cladding and structural materials due to its irradiation creep resistance, high tensile strength throughout irradiation, and low irradiation induced swelling. Irradiations at EBR-II with metal fuel demonstrated that HT-9 has a higher degree of resistance to FCCI than other fast reactor steels, e.g., austenitic D-9 [19].

Finally, the production of helium gas by alpha decay in the driver fuel and transmutation target was quantified along with the production of the fission gasses, krypton and xenon. Due to the threshold fission requirement, most of the americium in the targets is transmuted by neutron capture, rather than fission. This transmutation requires a series of successive neutron capture and decay reactions before americium is converted into fissile isotopes of plutonium and curium. In order to produce these fissile isotopes, a shorter lived intermediary non-fissile curium isotope has to be produced. For Am-241, this isotope is $\mathrm{Cm}-242$, whose production and decay $\left(\mathrm{T}_{1 / 2}=162.8\right.$ days $)$ is essentially in secular equilibrium with the short-lived beta decay of the neutron capture product Am-242. For Am-243, this isotope is Cm244 , which is long lived enough $\left(\mathrm{T}_{1 / 2}=18.1\right.$ years). Both Cm-242 and Cm-244 decay by emission of an alpha particle. The kinetic energy of this alpha particle is quickly lost by ionization interactions with atoms of the fuel matrix. Once the alpha particle is stopped, it will have picked up two electrons in its K-Shell, thus becoming a helium atom. These helium atoms accumulate in the fuel as a function of irradiation time. Also, the production of krypton and xenon fission gas is a function of burnup, which, in turn, is a function of irradiation time. This additional gas production requires quantification in order to determine the plenum height that impacts the thermal-hydraulic design of the reactor.

The fraction of gas that is released to the plenum depends on the level of fuel restructuring in the target pellet during the irradiation. Due to the high linear heat generation rates (LHGR), high fuel burnups and high fuel temperatures common to SFRs, significant fuel restructuring, swelling, and gas 
release have been observed for FFTF fuels. According to Waltar et al., SFR-MOX fuels, after a burnup of $100 \mathrm{MWD} / \mathrm{kg}$, will have released $85 \%$ of the gas to the plenum [20]. Wirtz describes SFR-MOX fuel degradation after $56 \mathrm{MWD} / \mathrm{kg}$ at $40 \mathrm{KW} / \mathrm{m}$ [21]. Simultaneously, the fuel forms radially-oriented crystals near the pellet centerline. At very high temperatures $\left(>2100{ }^{\circ} \mathrm{C}\right)$, radial transport by atomic diffusion (as well as vaporization) produces a higher concentration of plutonium near the centerline. The temperature and concentration gradient eventually cause the fuel to restructure, forming a hollow channel along the fuel centerline. The degree of restructuring is unknown for each target design. Given that the transmutation targets are placed on the core periphery, the peak temperatures experienced will not be as high as for the driver fuel. If the fuel degradation in the targets is less severe, the target pellet will have a higher internal pressure which could cause significant swelling. Swelling could make fuel-to-clad mechanical interaction (FCMI) more important than the gas pressure radial stresses. For this work, fuel restructuring is assumed to occur in the target pellet leading to $85 \%$ gas release. The partial pressure of helium, krypton, and xenon in the total plenum pressure is reported.

\section{Summary of Results}

A series of FORTRAN tools were developed to iterate the REBUS calculation until the peak fluence limit of $4.0 \times 10^{23} \mathrm{~cm}^{-2}$ is respected for each core design's fuel cycle calculation. Therefore, the cladding damage criterion is simultaneous satisfied with the core physics calculation. The driver fuel burnup $(\sim 100 \mathrm{MWD} / \mathrm{kg})$, achieved at this fluence, was within the range for SFR-MOX fuels tested at EBR-II and FFTF [20].

Since the REBUS calculation does not report total number of alpha decays as one of its outputs, a FORTRAN tool was developed to recreate the fuel buildup/depletion algorithm performed by REBUS. This was done in order to reproduce the alpha decay history of each actinide isotope as a function of irradiation time. This depletion algorithm uses an exponential matrix method similar to that used by the ORIGEN code [4]. The code calculates the number density of each actinide isotope as a function of discrete time steps. With the depletion history of the fuel known in much finer time steps than reported in the REBUS output, these number densities are then converted into alpha decay activity. For the helium calculation, pure exponential decay is assumed within the time step. This alpha decay is numerically integrated in time for each time step. The total cumulative number of alpha disintegrations throughout the entire irradiation is found by summing the integrated alpha decay over all time steps. The total integrated alpha activity corresponds to the total number of helium atoms generated.

The thermal performance of the RH-SFR fuel was evaluated. For this analysis, the axial LHGR distribution for the hottest fuel assembly at BOEC was used to determine the axial fuel centerline and inner cladding temperature profiles. The sodium coolant channel surrounding a "typical" fuel pin within this hottest assembly was considered. The Schad-Modified Nusselt correlation was used to calculate film temperature rise and, thus, clad surface temperature as a function of axial height from the coolant inlet at the bottom of the active core [20][22]. Clad inner wall temperature and fuel surface and centerline temperature were then calculated.

\subsection{Homogeneous Recycle}

The fuel cycle performance of the homogeneous ABR reference calculation matches that described by Hoffman et al. The mass throughput of this core design is described in Table 4 and compared with values from the ANL-AFCI-177 report [3]. Also shown is the production rate of heavy metal normalized to fission energy produced in the fuel for the PWR fuel assembly assessed earlier in the TRITON calculation. 
As can be seen from the table, the reference calculation closely matches the values found in the report. It is interesting to note that the ABR transuranic mass consumption rate is approximately equal to the rate of transuranic production by the PWR-UOX fuel. The transuranic consumption rate may be increased by decreasing the $\mathrm{CR}$.

Table 4. Transuranic mass feed rate comparison for the reference ABR.

\begin{tabular}{|c|c|c|c|}
\hline & ABR & Ref. [3] & PWR-UOX \\
\hline TRU Charge Rate (kg/MWY) & 0.6923 & 0.6760 & $\mathrm{n} / \mathrm{a}$ \\
\hline Heavy Metal Charge Rate (kg/MWY) & 2.7651 & 2.7000 & $\mathrm{n} / \mathrm{a}$ \\
\hline TRU Consumption Rate (kg/MWY) & 0.0768 & 0.0831 & -0.0951 \\
\hline Minor Actinide Consumption Rate (kg/MWY) & 0.0134 & -- & -0.0032 \\
\hline Heavy Metal Consumption Rate (kg/MWY) & 0.3535 & -- & -7.3050 \\
\hline
\end{tabular}

Figure 3 shows the axial temperature distributions calculated in the hot channel: bulk coolant, cladding inner and outer surface, fuel surface and fuel centerline temperatures. The cold, un-irradiated fuel thermal conductivity and fuel dimensions were used in this calculation.

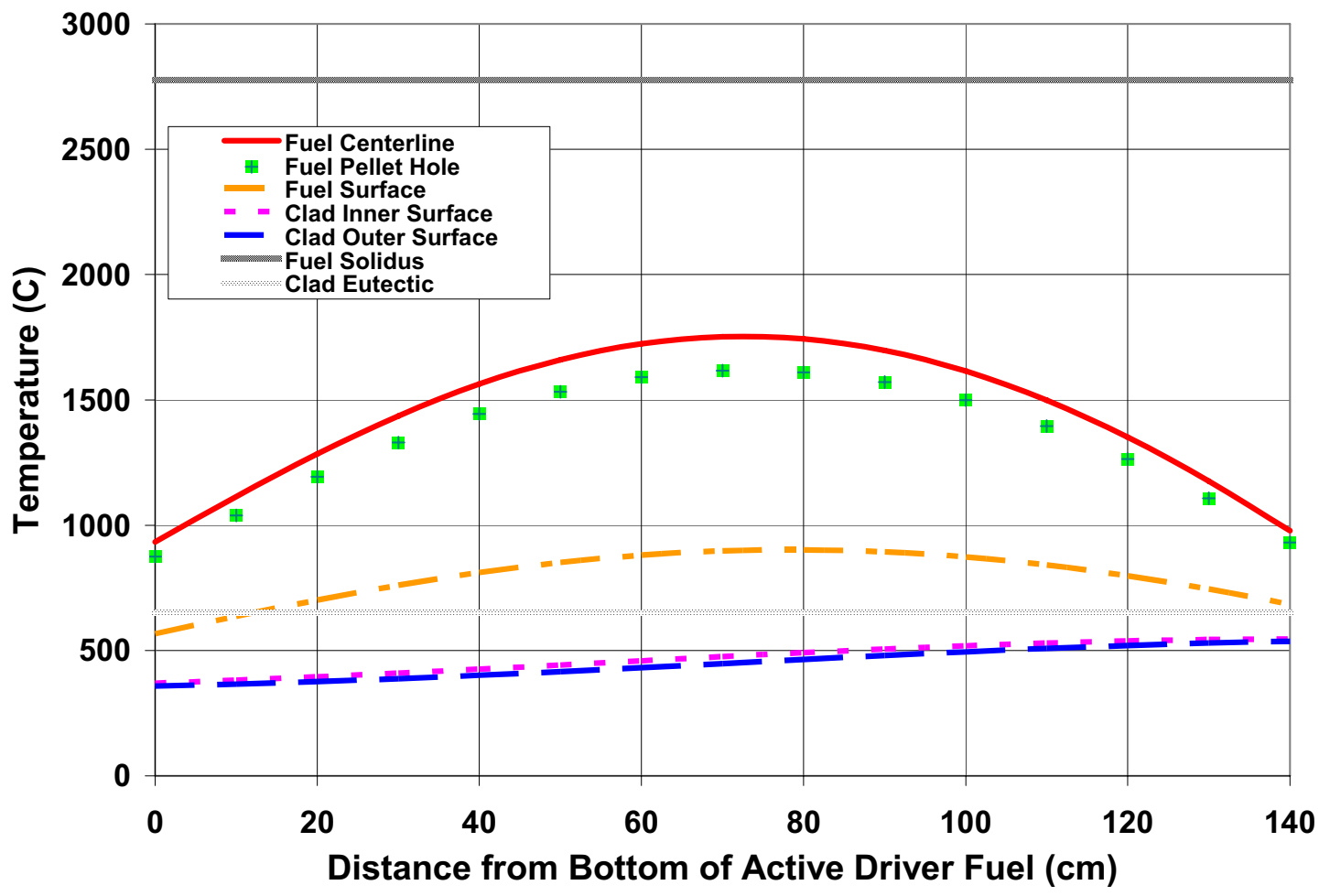

Figure 3. Axial temperature distributions for the hottest fuel rod.

The Hoffman report was focused primarily on fuel cycle trends and did not include a thermalhydraulic analysis for this core design. Waltar quotes the peak driver fuel and cladding temperatures for FFTF as $2,250{ }^{\circ} \mathrm{C}$ and $670{ }^{\circ} \mathrm{C}$, respectively [20]. FFTF was operated at approximately the same coolant and fuel temperatures as the ABR. Also, the S-PRISM and ABR $(\mathrm{CR}=0.75)$ fuel designs were similar to what was used at FFTF. The peak LHGR for FFTF was $42 \mathrm{~kW} / \mathrm{m}$ [20]. The calculated peak LHGR for the ABR reference is $26.9 \mathrm{~kW} / \mathrm{m}$. This value is closer to the value reported by Hoffman of $30.1 \mathrm{~kW} / \mathrm{m}$ 
[3]. Therefore, it follows that the ABR peak fuel temperature should be less than that observed at FFTF. This is shown in Figure 3. It is apparent that the hot channel analysis methodology accurately predicts peak fuel and cladding temperatures within the range of practical experience. Therefore, it is deemed a reasonable tool for estimating the thermal conditions of the ABR or RH-SFR driver fuel and transmutation targets.

As demonstrated by Figure 3, SFR oxide fuel operates relatively close to its melting point. This explains much of the inter-diffusion and restructuring that takes place. The gas generation calculation for the ABR is graphed in Figure 4 in terms of partial pressures of the total plenum pressure.

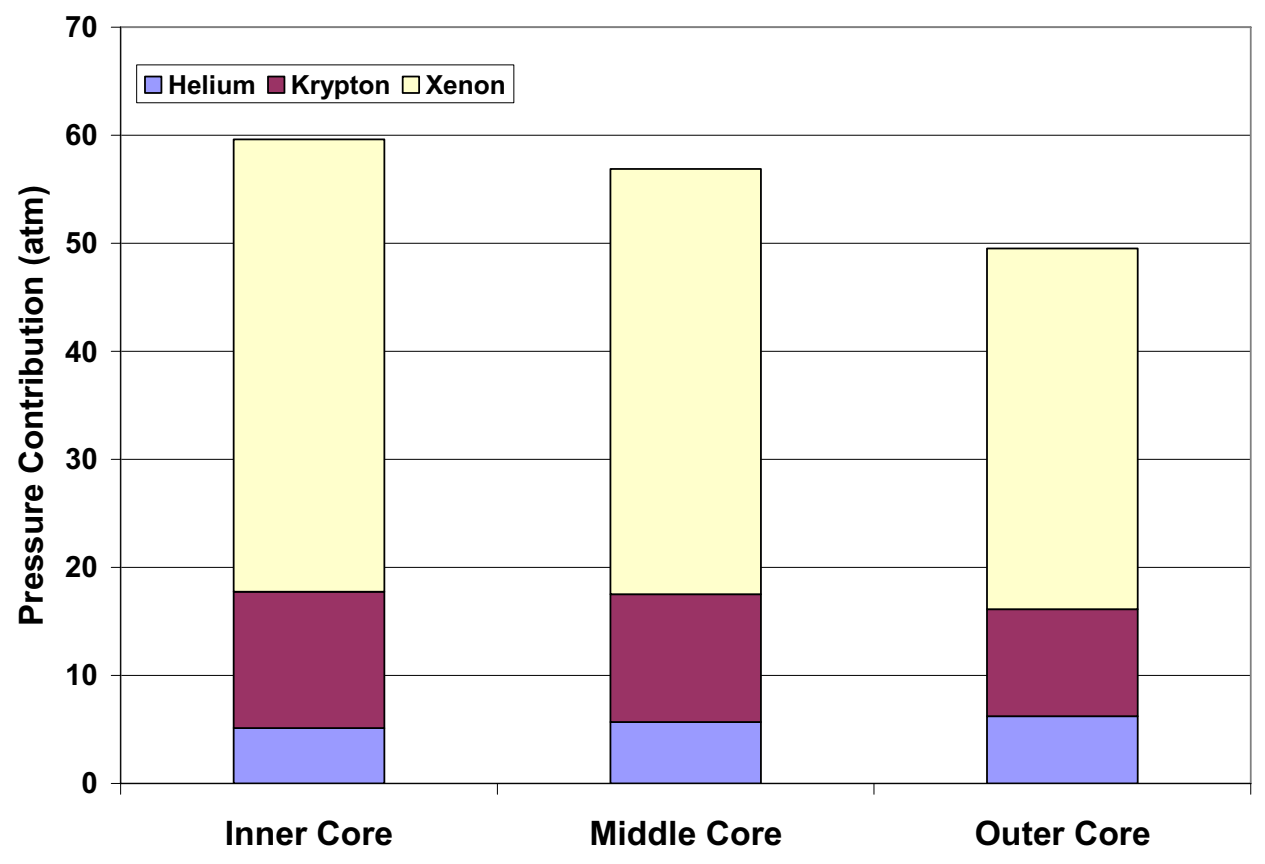

Figure 4. Partial pressure contributions to the total plenum pressure for an average ABR fuel pin.

Typical plenum pressures at discharge for oxide-fueled SFR fuel pins are between 60 and 100 atmospere (atm) [20]. The strain limit and creep failure criterion for HT-9 cladding depicts a fuel plenum height of approximately 1.5 times the height of the active fuel [20]. For this ABR design, this ratio is 1.26. For the RH-SFR cases, a gas release fraction of $85 \%$ is assumed. Also, it is assumed that $27 \%$ of all fissions result in the accumulation of a gas atom at the end of fuel life, after decay effects of non-gas fission products transitioning into gas. Given the similarity of the gas production calculation to values quoted in the literature, the gas generation calculation tool is reasonable for estimating the actual expected gas pressures for any given heterogeneous design.

\subsection{Six Targets}

A transuranic destruction efficiency $\left(\mathrm{E}_{\mathrm{TRU}}\right)$ is defined by the fraction of the initial transuranic mass in the targets at beginning of life that is destroyed by fission. The $\mathrm{E}_{\mathrm{TRU}}$ indicates the ability of the targets to completely remove the mass associated with the minor actinides from the fuel cycle. The overall $\mathrm{E}_{\mathrm{TRU}}$ value of the six $\mathrm{MgO}$ target case was found to be $15 \%$. Conversely, the minor actinide destruction efficiency $\left(\mathrm{E}_{\mathrm{MA}}\right)$ is defined as the fraction of the initial minor actinide mass that is removed from the fuel cycle by either a fission or a capture reaction. The $\mathrm{E}_{\mathrm{MA}}$ indicates the ability of the targets to convert the form of the minor actinide mass into either a fission product or transmutation byproduct isotopes, which 
is mostly plutonium. The $\mathrm{E}_{\mathrm{MA}}$ of the six $\mathrm{MgO}$ target cases is $36 \%$. Therefore, it is clear that the targets can displace $36 \%$ of the minor actinide mass charged to fresh target assemblies.

However, the minor actinide mass (Np-237 and a small amount of Am-241) present in the fresh driver fuel doubles $\left(\mathrm{E}_{\mathrm{MA}} \sim-200 \%\right)$ during the course of the driver fuel's irradiation. The minor actinide production by the active core is due to successive neutron capture reactions in $\mathrm{Pu}-241$ and $\mathrm{Am}-241$. Hence, the net minor actinide consumption rate is $0.0105 \mathrm{~kg} /$ megawatt year (MWY). This value is slightly less than the ABR which consumes minor actinides at the rate of $0.0134 \mathrm{~kg} / \mathrm{MWY}$.

The equilibirium cycle enrichment of the driver fuel was similar to that of the ABR. However, the MgO-6 targets had a volumetric enrichment of 97\%. The enrichment is defined in terms of volume percent, as opposed to weight percent. This is done in order to make an equal comparison between target matrices of different mass densities. The fuel performance parameters of the driver fuel and transmutation target are shown in Table 5.

Table 5. Irradiation performance aspects of the MgO-6 case.

\begin{tabular}{|c|c|c|}
\hline & \multicolumn{2}{|c|}{ Six MgO Targets } \\
\hline Conversion Ratio & \multicolumn{2}{|c|}{0.712} \\
\hline & Driver & Target \\
\hline Peak Fuel Centerline Temp $\left({ }^{\circ} \mathrm{C}\right)$ & 2055 & 924 \\
\hline Peak Inner Cladding Temp $\left({ }^{\circ} \mathrm{C}\right)$ & 533 & 441 \\
\hline Peak LHGR $(\mathrm{kW} / \mathrm{m})$ & 25.9 & 12.6 \\
\hline Peak Fluence $\left(10^{23} \mathrm{~cm}^{-2}\right)$ & 3.99 & 3.70 \\
\hline Enrichment $(\%)$ & $21.6 \%$ & $97.3 \%$ \\
\hline
\end{tabular}

Six is the absolute minimum number of targets needed to consume the minor actinides at approximately the same rate as the ABR. For all practical purposes, the six targets are filled completely with $\mathrm{MA}-\mathrm{O}_{2}$ with no matrix at all. This is the special case discussed above in the fuel cycle assumptions section where the minimum number of target assemblies is found by reducing the matrix volume to zero. As seen in Table 5, the transmutation target's centerline and fuel temperature fall well below these values for the RH-SFR driver fuel or the ABR. Also, the peak fast fluence in the targets has been maintained to be as close to the $4.0 \times 10^{23} \mathrm{~cm}^{-2}$ limit as possible without going over it. However, because very little of the minor actinide mass was destroyed by fission, most of it was transmuted into $\mathrm{Pu}-238, \mathrm{Pu}-242, \mathrm{Cm}-$ 242 and Cm-244. The buildup and depletion behavior of these isotopes is discussed in Section 5.5. The primary decay mode for all of these isotopes is by alpha emission. Therefore, a significant amount of helium is generated. The calculated plenum gas pressure for the six targets, at the end of their 10 cycle lifetime, is $300 \mathrm{~atm}$. Seventy five percent of this gas is helium resulting from alpha particle emission. This pressure is three times higher than what can be considered feasible. To reduce the gas pressure to $100 \mathrm{~atm}$, a gas plenum of five meters would be required, which is unacceptable from a thermal-hydraulics standpoint. Therefore, the number of targets in the RH-SFR design is multiplied by three.

\subsection{Eighteen Targets}

Similar to MgO-6, the 18-target cases showed very little power and temperature peaking in the targets. The irradiation performance aspects of these cases are shown in Table 6. Also, as is the case for $\mathrm{MgO}-6$, the fluence limits are observed at all times. The peak fuel centerline temperatures for the UOX$18 \mathrm{f}$ and $\mathrm{MgO}-18 \mathrm{f}$ cases are both about $300{ }^{\circ} \mathrm{C}$ higher than the peak centerline temperatures of the ABR core. This is because twelve of the outer core driver fuel assemblies are replaced by transmutation targets (Figure 1). The transmutation targets do not have as much reactivity as the driver fuel, and, thus, do not produce as much power. This puts more of the power generation burden on the driver fuel. The higher power densities and LHGR in the driver fuel causes higher fuel temperatures. 
The MgO-18r case has the additional twelve transmutation target assemblies located in the radial reflector outside of the core. Therefore, the extra power generation burden is removed from the driver fuel. In fact, any power that the transmutation targets generate removes some of the burden off of the driver fuel. However, the reflector region places the transmutation targets in a lower flux than when they were in the outer row of driver fuel. Therefore, the transmutation efficiency is less if the targets are placed on the same row as the driver fuel. The $\mathrm{E}_{\mathrm{TRU}}$ and $\mathrm{E}_{\mathrm{MA}}$, for the $\mathrm{MgO}-18 \mathrm{r}$ case, is $11.1 \%$ and 37.44 percent, respectively.

Table 6. Irradiation performance aspects of RH-SFR cases with 18 transmutation targets.

\begin{tabular}{|c|c|c|c|c|c|c|}
\hline & \multicolumn{2}{|c|}{ UOX-18f } & \multicolumn{2}{c|}{ MgO-18f } & \multicolumn{2}{c|}{ MgO-18r } \\
\hline Conversion Ratio & \multicolumn{2}{|c|}{0.757} & \multicolumn{2}{c|}{0.709} & \multicolumn{2}{c|}{0.721} \\
\hline & Driver & Target & Driver & Target & Driver & Target \\
\hline Peak Fuel Centerline Temp $\left({ }^{\circ} \mathrm{C}\right)$ & 2262 & 765 & 2265 & 497 & 2054 & 492 \\
\hline Peak Inner Cladding Temp $\left({ }^{\circ} \mathrm{C}\right)$ & 559 & 395 & 560 & 391 & 685 & 391 \\
\hline Peak LHGR $(\mathrm{kW} / \mathrm{m})$ & 29.1 & 6.1 & 29.1 & 4.0 & 25.9 & 3.5 \\
\hline Peak Fluence $\left(10^{23} \mathrm{~cm}^{-2}\right)$ & 3.95 & 3.26 & 3.94 & 3.17 & 3.95 & 3.25 \\
\hline Enrichment $(\%)$ & $21.8 \%$ & $27.6 \%$ & $22.3 \%$ & $27.5 \%$ & $21.5 \%$ & $35.1 \%$ \\
\hline
\end{tabular}

When comparing the UOX case with the MgO cases, it is important to note the higher CR caused by the uranium matrix. The fertile-free nature of the $\mathrm{MgO}$ targets gives an inherent reduction in the core $\mathrm{CR}$. As discussed in the introduction, adding uranium increases the CR. The plutonium breeding decreases the $\mathrm{E}_{\mathrm{TRU}}$ of the targets. The $\mathrm{E}_{\mathrm{TRU}}$ for $\mathrm{MgO}-18 \mathrm{f}$ is $14.4 \%$. Alternatively, the UOX-18f targets produce $2 \%$ more total transuranic than they consume. However, the $\mathrm{E}_{\mathrm{MA}}$ for both cases is about $35 \%$.

The higher thermal conductivity of the magnesium oxide gives both $\mathrm{MgO}$ cases centerline temperatures that are approximately $270{ }^{\circ} \mathrm{C}$ lower than the UOX case.

The transmutation target gas pressures for the 18 target cases are given in Table 7. The MgO-18r case exhibits a greater helium contribution. This is due to higher minor actinide enrichment, than the $18 \mathrm{f}$ cases, and corresponding greater $\mathrm{Cm}-244$ concentration. The UOX-18f produces more fission product gasses. The higher gas production of the UOX-18f case is linked to the in-situ production and fissioning of Pu-239.

Table 7. Helium and fission product gas partial pressures (in atm) in the fuel pin plenum.

\begin{tabular}{|c|c|c|c|}
\hline & UOX-18f & MgO-18f & MgO-18r \\
\hline Helium & 65.11 & 70.38 & 84.10 \\
\hline Krypton & 6.58 & 3.86 & 3.81 \\
\hline Xenon & 22.76 & 16.07 & 16.04 \\
\hline Total & 94.45 & 90.30 & 103.94 \\
\hline
\end{tabular}

\subsection{Forty-Eight Targets}

Similar to the MgO-6 and MgO-18 cases, the 48-target cases showed very little power and temperature peaking in the targets. The irradiation performance aspects of these cases are shown in Table 8. Also, the fluence limits are observed at all times, which is done automatically by the code by the combined REBUS and FORTRAN tools. The peak driver fuel temperatures are within $50{ }^{\circ} \mathrm{C}$ of the $\mathrm{ABR}$, MgO-6 and MgO-18r cases. All of these cases have the same number of driver assemblies. Therefore, the radial power distribution of the driver core is about the same. Both UOX and $\mathrm{MgO}$ targets have very low minor actinide enrichment $(\sim 10 \%)$. Therefore, the power density in the transmutation targets is also 
very small compared to the driver fuel. In fact, the difference in transmutation target fuel centerline and surface temperature is only about $200{ }^{\circ} \mathrm{C}$.

Table 8. Irradiation performance aspects of of RH-SFR cases with 48 transmutation targets.

\begin{tabular}{|c|c|c|c|c|}
\hline & \multicolumn{2}{|c|}{ UOX-48r } & \multicolumn{2}{c|}{ MgO-48r } \\
\hline Conversion Ratio & \multicolumn{2}{|c|}{0.865} & \multicolumn{2}{c|}{0.734} \\
\hline & Driver & Target & Driver & Target \\
\hline Peak Fuel Centerline Temp $\left({ }^{\circ} \mathrm{C}\right)$ & 2021 & 599 & 2007 & 533 \\
\hline Peak Inner Cladding Temp $\left({ }^{\circ} \mathrm{C}\right)$ & 533 & 378 & 393 & 367 \\
\hline Peak LHGR $(\mathrm{kW} / \mathrm{m})$ & 25.1 & 3.7 & 25.8 & 1.5 \\
\hline Peak Fluence $\left(10^{23} \mathrm{~cm}^{-2}\right)$ & 3.95 & 3.74 & 3.94 & 3.64 \\
\hline Enrichment $(\%)$ & $19.9 \%$ & $8.8 \%$ & $21.1 \%$ & $9.8 \%$ \\
\hline
\end{tabular}

It is significant to note that the $\mathrm{E}_{\mathrm{MA}}$ found for the UOX-48r and $\mathrm{MgO}-48 \mathrm{r}$ was $31 \%$ and $41 \%$, respectively. These values are roughly close to the $\sim 40 \%$ destruction efficiency quoted by Buiron et al. [23]. Buiron investigated a $3600 \mathrm{MWth}$ SFR surrounded by a radial reflector of depleted uranium assemblies containing minor actinides. Buiron investigated the transmutation performance of this core design by considering two transmutation target minor actinide enrichments: $10 \%$ and also $40 \%$.

One significant difference between the UOX and $\mathrm{MgO}$ cases is that the plutonium breeding within the 48 UOX targets creates a significant feedback of fissile material in the fuel cycle. Considering the low minor actinide concentration in the 48 targets, the UOX-48r can be viewed as the ABR core wrapped in an external radial blanket of U-238. In order to maintain the net transuranic burning criterion, an inert matrix must be used if 48 targets are to be assumed.

The 48-target case may have specific advantages to fuel performance because the combined gas generation of helium, krypton and xenon is only $36.4 \mathrm{~atm}$ for MgO-48 and $38.2 \mathrm{~atm}$ for UOX-48.

However, because the fuel temperature of the targets is so low, it is unlikely that there will be enough fuel restructuring to yield $85 \%$ gas release. Therefore, it is possible that most of this pressure may be retained within the pellet.

\subsection{Separating Curium}

The irradiation performance aspects of targets without curium and the higher mass actinides are given in Table 9. As expected, there is little difference between the fuel and cladding thermal performance or cladding damage performance. The separation of curium after each recycle gives smaller transmutation target minor actinide enrichment. The absence of curium in the fuel results in a reduction in the overall helium production. The total pressure in the curium free case is 69.9 atm compared to 90.3 atm when it is included in the fuel.

The percent breakdown of contributing parent atom to helium production is given in Figure 5 and Figure 6. From these figures, it is apparent that removing curium after each irradiation reduces the helium gas production by $20 \%$ of the helium production, which is responsible for about $20 \mathrm{~atm}$ of total plenum pressure. 
Table 9. Irradiation performance aspects of RH-SFR transmutation targets with and without curium.

\begin{tabular}{|c|c|c|c|c|}
\hline & \multicolumn{2}{|c|}{ UOX-18f } & \multicolumn{2}{c|}{ UOX-18f-Am } \\
\hline Conversion Ratio & \multicolumn{2}{|c|}{0.757} & \multicolumn{2}{c|}{0.734} \\
\hline & Driver & Target & Driver & Target \\
\hline Peak Fuel Centerline Temp $\left({ }^{\circ} \mathrm{C}\right)$ & 2262 & 765 & 2332 & 488 \\
\hline Peak Inner Cladding Temp $\left({ }^{\circ} \mathrm{C}\right)$ & 559 & 395 & 565 & 387 \\
\hline Peak LHGR $(\mathrm{kW} / \mathrm{m})$ & 29.1 & 6.1 & 30.2 & 5.0 \\
\hline Peak Fluence $\left(10^{23} \mathrm{~cm}^{-2}\right)$ & 3.95 & 3.26 & 3.95 & 3.74 \\
\hline Enrichment $(\%)$ & $21.8 \%$ & $27.6 \%$ & $21.9 \%$ & $21.1 \%$ \\
\hline
\end{tabular}

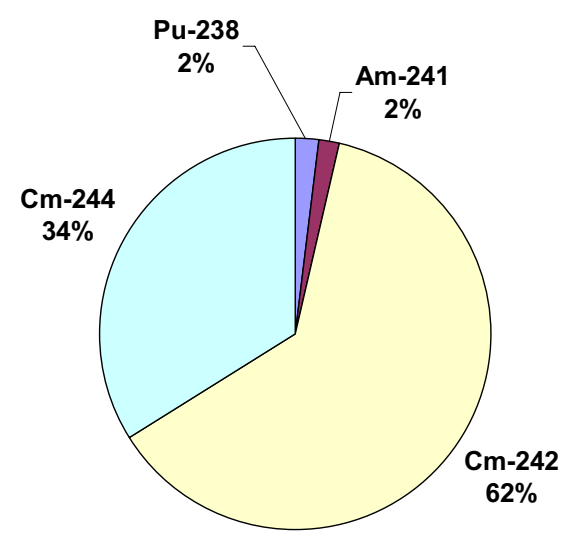

Figure 5. Percent helium gas contributions by parent isotope for the UOX-18f case (Cm retained).

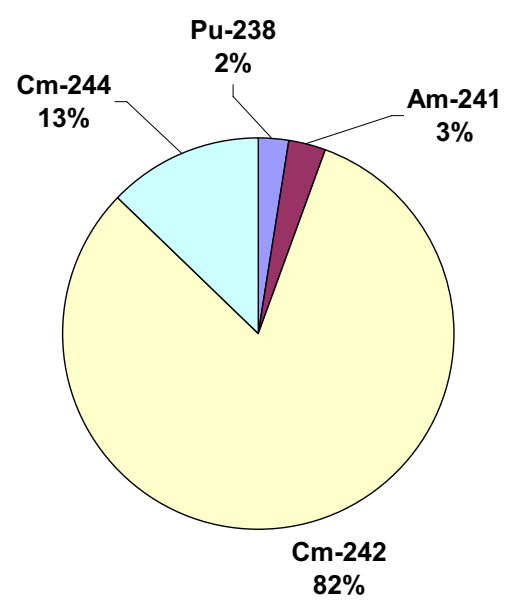

Figure 6. Percent helium gas contributions by parent isotope for the UOX-18f-Am case (Cm discarded). 
Though separating curium gives a distinct advantage with respect to gas production, $\mathrm{Cm}-244$ still produces $13 \%$ of the overall helium. This is because $\mathrm{Cm}-244$ is readily bred back into the fuel cycle through transmutation of Am-243. Figure 7 and Figure 8 show the buildup and depletion of the most important actinides in the two target cases.

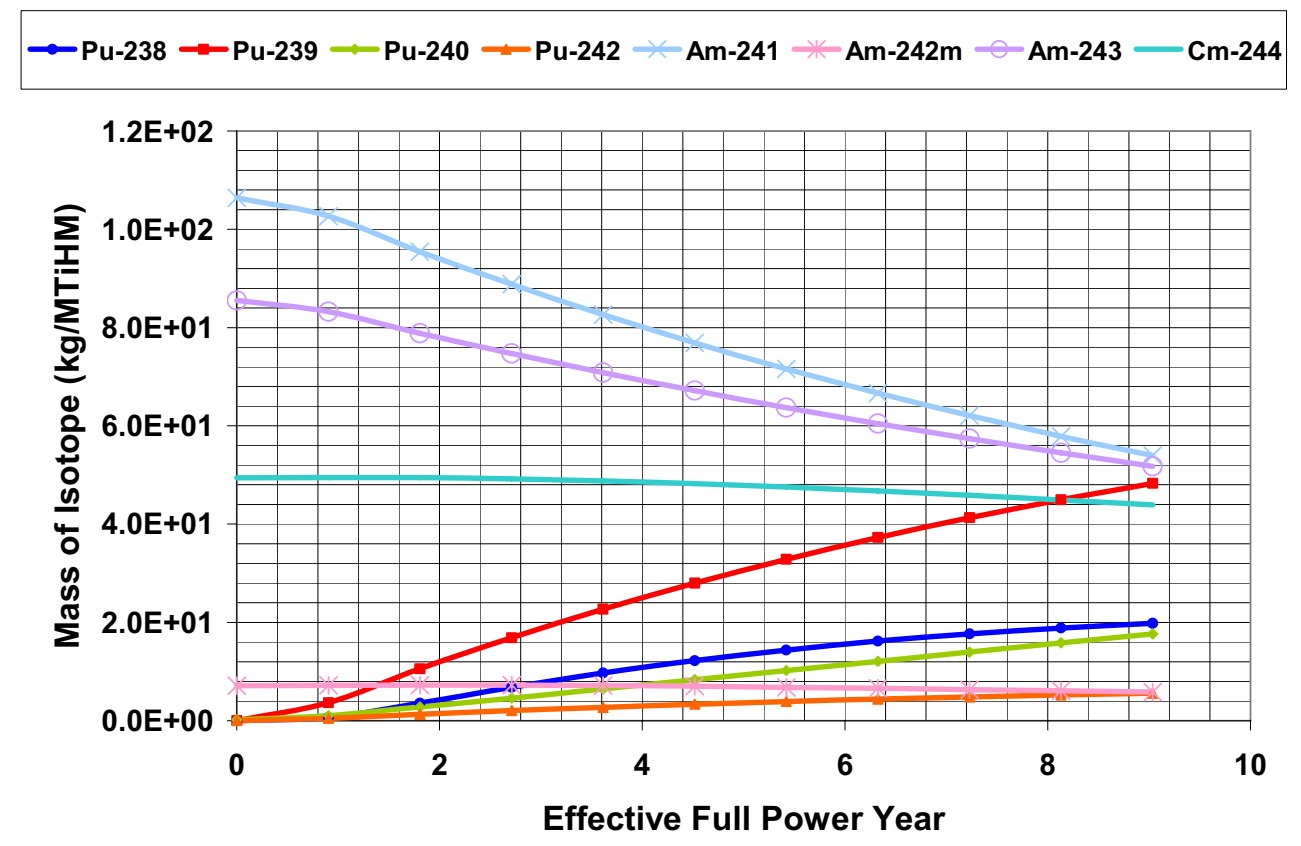

Figure 7. Buildup and depletion of transmutation target isotopes in UOX-18f $(\mathrm{Cm}$ retained).

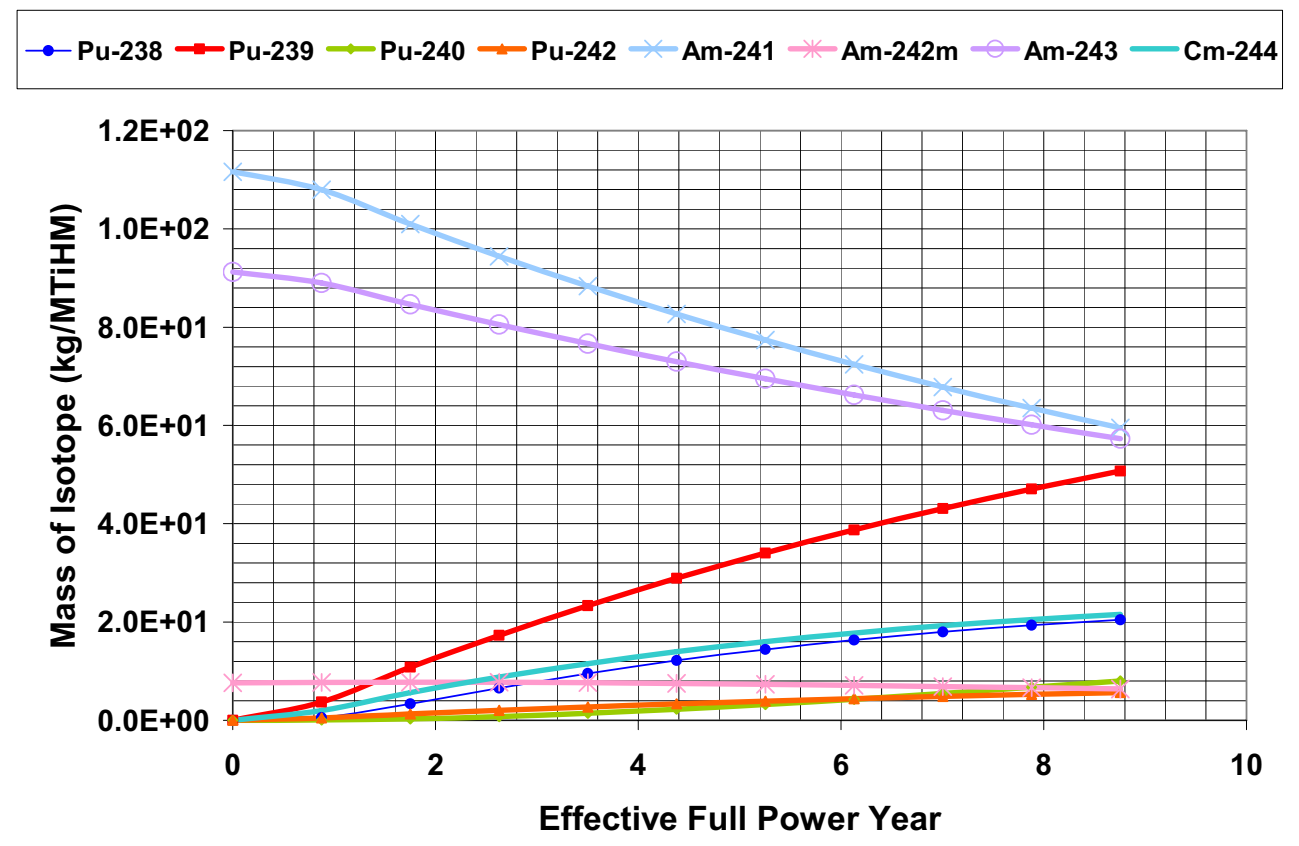

Figure 8. Buildup and depletion of transmutation target isotopes in UOX-18f-Am (Cm discarded). 
As can be seen from the figures, $\mathrm{Cm}-244$ is essentially bred from Am-243 when it is not included in the initial transuranic charge. If this Cm-244 is separated with every reactor pass, the RH-SFR (UOX$18 \mathrm{f}-\mathrm{Am}$ ) will generate $\mathrm{Cm}-244$ at a rate of $0.0062 \mathrm{~kg} / \mathrm{MWY}$. However, if it is included, there is a slight net destruction over the course of the irradiation.

\subsection{Magnesium Oxide and Uranium Oxide Matrix}

As previously discussed, the plutonium breeding contribution of uranium in the targets does not significantly impact the core conversion ratio until many targets are introduced. Such is the case of the UOX-48r scenario. For comparison purposes, Figure 9 through 14 are provided to show the buildup and depletion of transuranic isotopes in a uranium oxide target and a magnesium oxide target matrix. The mass of each isotope is normalized per metric tons of initial TRU (MTiTRU) in the targets.

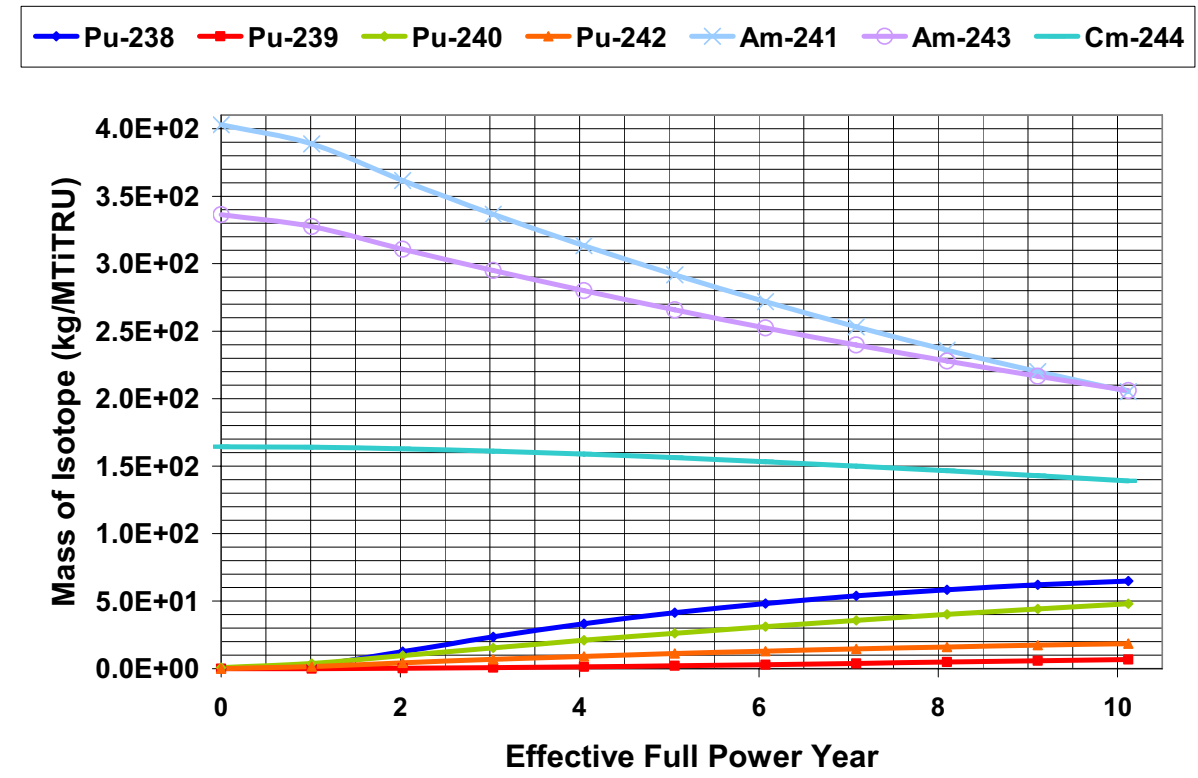

Figure 9. Buildup and depletion of transmutation target isotopes in $\mathrm{MgO}-6 \mathrm{f}$. 


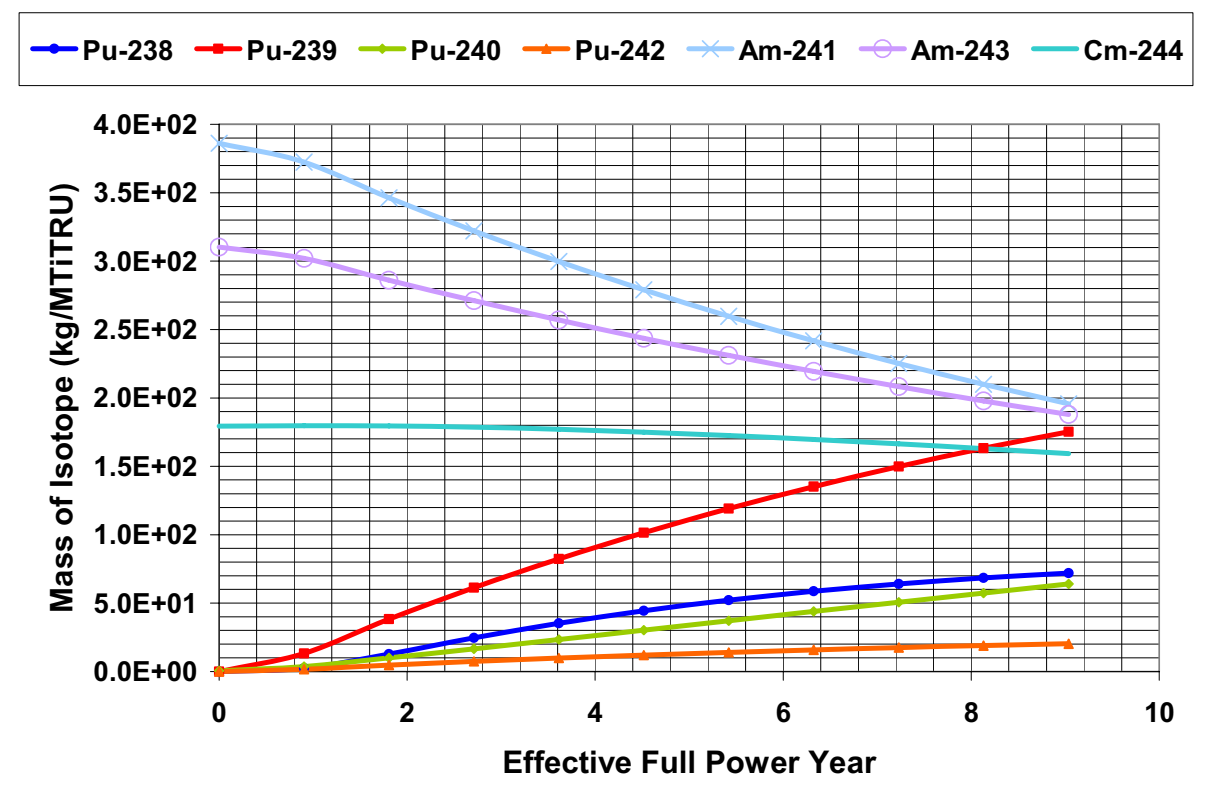

Figure 10. Buildup and depletion of transmutation target isotopes in UOX-18f.

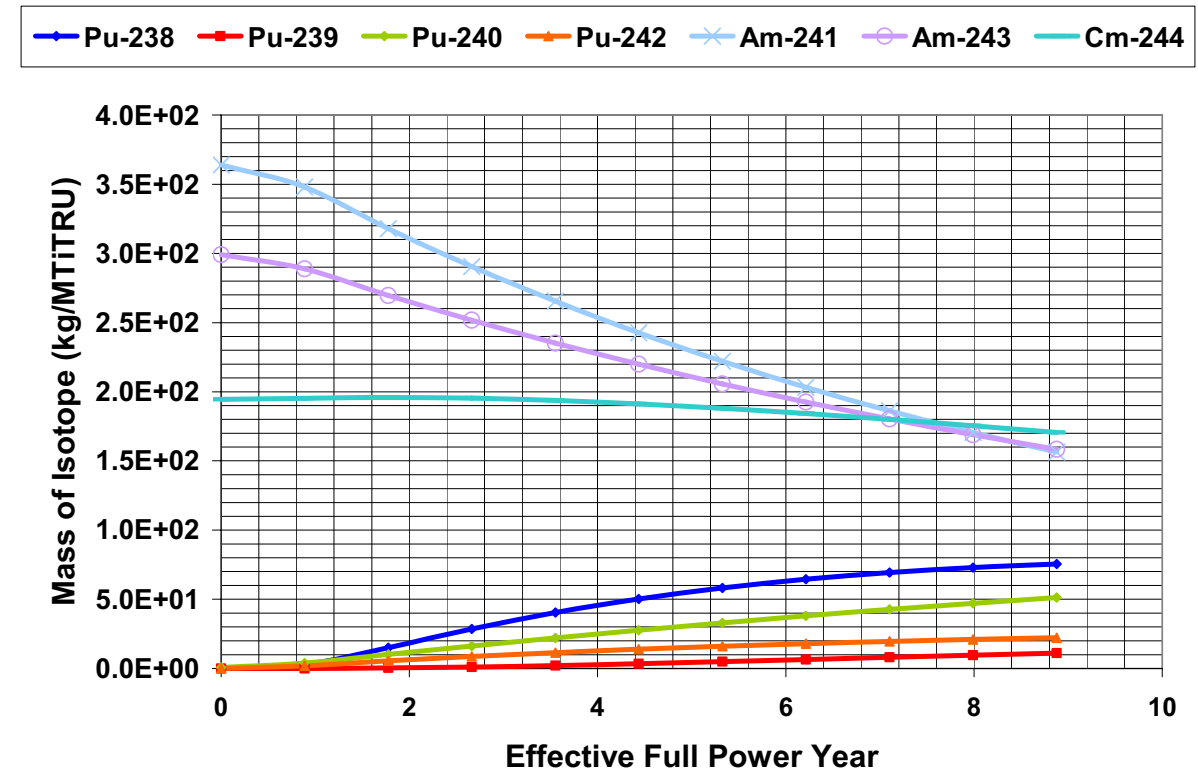

Figure 11. Buildup and depletion of transmutation target isotopes in $\mathrm{MgO}-18 \mathrm{f}$. 


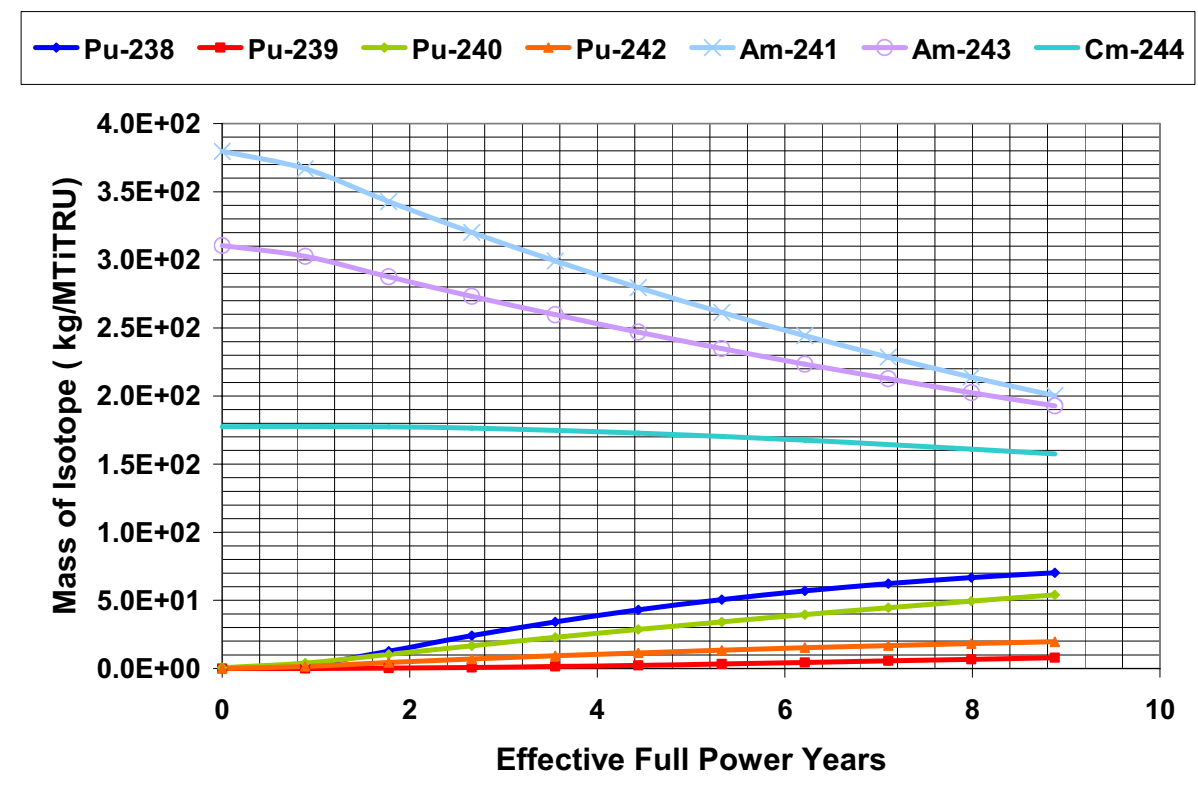

Figure 12. Buildup and depletion of transmutation target isotopes in MgO-18r.

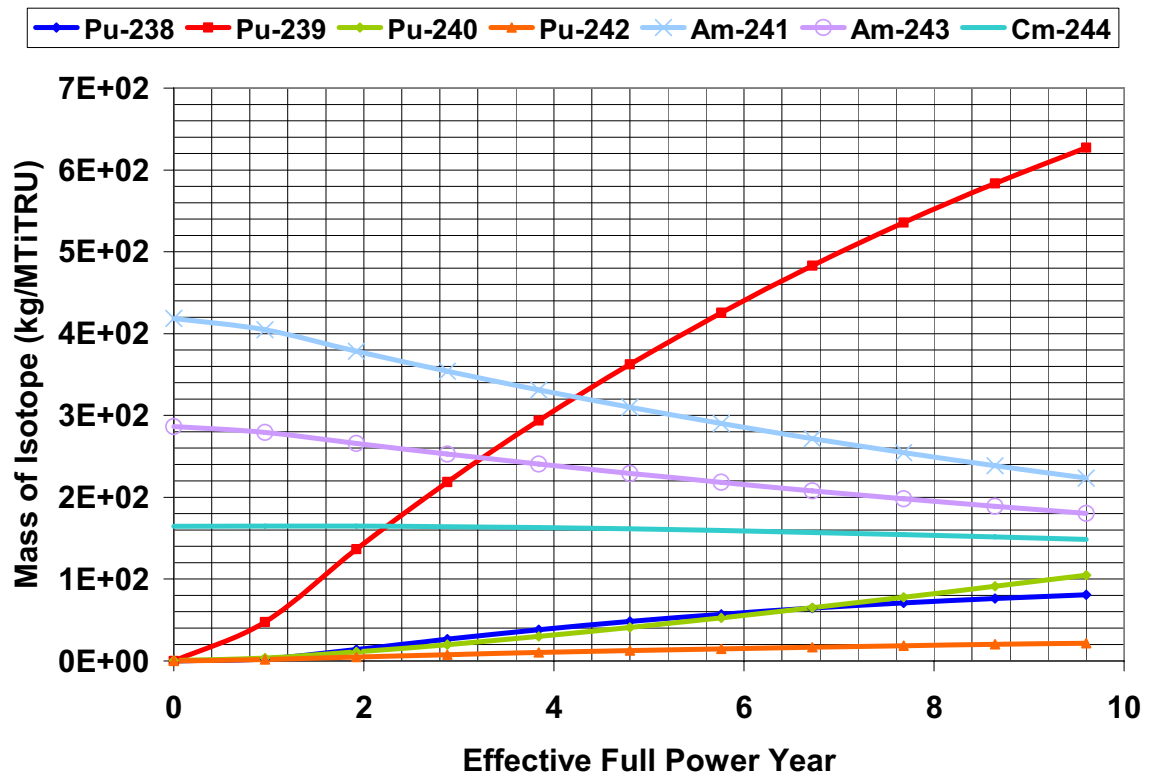

Figure 13. Buildup and depletion of transmutation target isotopes in UOX-48. 


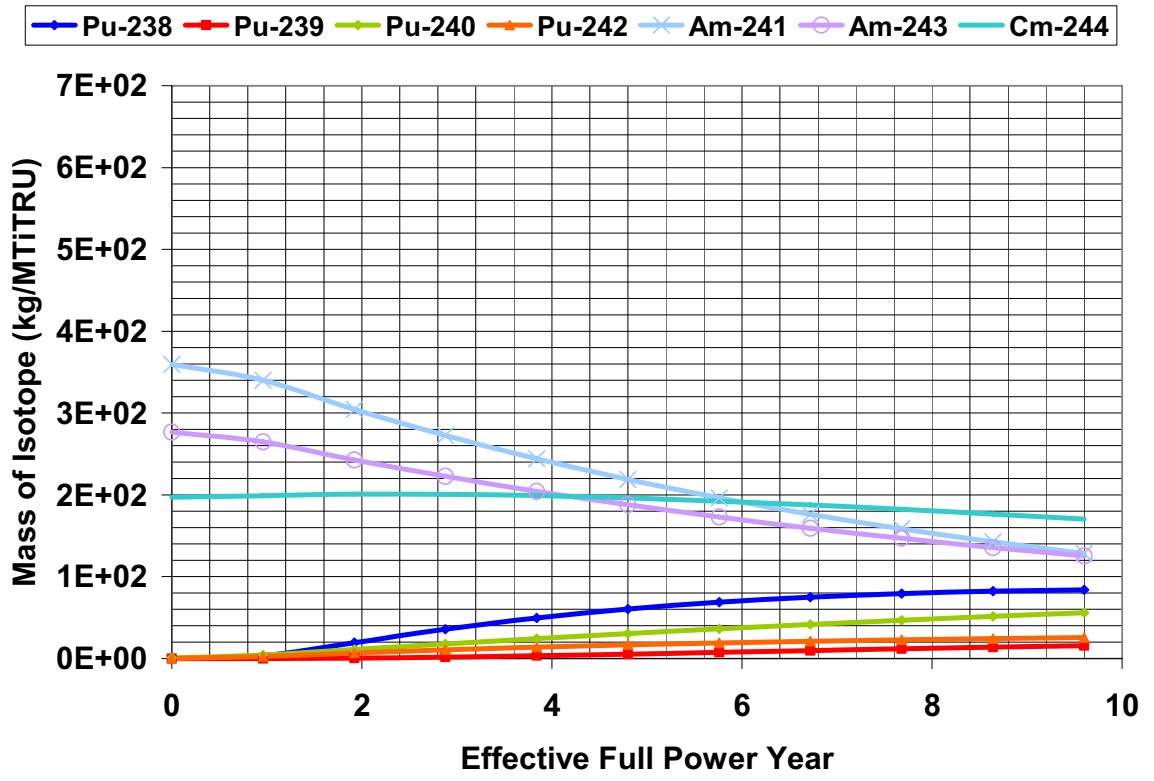

Figure 14. Buildup and depletion of transmutation target isotopes in MgO-48. 


\subsection{Composition Range of Analyzed Heterogeneous Designs}

This preliminary comparative analysis has revealed that the maximum allowable minor actinide enrichment in the transmutation targets should be kept to below 35 volume percent. This is the case for 18 transmutation targets placed in the reflector region of the core. The lowest minor actinide enrichment in the targets is 10 volume percent. This is the case for 48 transmutation targets placed in the reflector region of the core.

The dominating factor for the upper bound is the helium and fission gas pressure buildup as the combined result of burnup and transmutation. Because of the low power density in the targets, the pellet centerline and surface temperatures were all calculated to be well within the point of melting or FCCI criteria. The choice to use a UOX matrix in the transmutation targets increased the total core CR in all cases where it was used. However, this effect was only significant in the 48-target case. Separating the curium does decrease the helium gas produced by $\mathrm{Cm}-244$ during the irradiation. However, this decision results in a net generation of curium isotopes as opposed to a net destruction, if curium is not separated.

An elemental breakdown of the transmutation target's minor actinide component is given in Table 10. The isotopic breakdown is given in Table 11. This description is an approximate representation of the actinide vector observed in all of the cases analyzed. Small variations in the depletion/buildup behavior, corresponding to slight differences in cycle length, neutron spectrum, flux intensity, are expected to create slight differences in these values for each RH-SFR design.

Table 10. General elemental composition (w/o) of the transmutation targets' transuranic component.

\begin{tabular}{|l|l|l|}
\hline & Retain $\mathrm{Cm}^{*}$ & Discard Cm** \\
\hline Neptunium & $0.01 \%$ & $0.02 \%$ \\
\hline Plutonium & $0.06 \%$ & $0.00 \%$ \\
\hline Americium & $72 \%$ & $99.98 \%$ \\
\hline Curium & $28 \%$ & $0.00 \%$ \\
\hline Berkelium & $0.00 \%$ & $0.00 \%$ \\
\hline Californium & $0.02 \%$ & $0.00 \%$ \\
\hline
\end{tabular}


Table 11. General isotopic composition (w/o) of the transmutation targets' transuranic component.

\begin{tabular}{|l|l|l|}
\hline & Retain Cm* & Discard Cm** \\
\hline $\mathrm{Pu}-238$ & $0.00019 \%$ & $0.00010 \%$ \\
\hline $\mathrm{Pu}-239$ & $0.00078 \%$ & $0.00062 \%$ \\
\hline $\mathrm{Pu}-240$ & $0.05984 \%$ & $0.00000 \%$ \\
\hline $\mathrm{Pu}-241$ & $0.00001 \%$ & $0.00000 \%$ \\
\hline $\mathrm{Pu}-242$ & $0.00002 \%$ & $0.00003 \%$ \\
\hline $\mathrm{Am}-241$ & $38.60942 \%$ & $53.02515 \%$ \\
\hline $\mathrm{Am}-$ & & \\
$242 \mathrm{~m}$ & $2.57497 \%$ & $3.60893 \%$ \\
\hline $\mathrm{Am}-243$ & $31.02462 \%$ & $43.34691 \%$ \\
\hline $\mathrm{Cm}-242$ & $0.05537 \%$ & $0.00004 \%$ \\
\hline $\mathrm{Cm}-243$ & $0.11011 \%$ & $0.00000 \%$ \\
\hline $\mathrm{Cm}-244$ & $17.93715 \%$ & $0.00000 \%$ \\
\hline $\mathrm{Cm}-245$ & $5.42602 \%$ & $0.00000 \%$ \\
\hline $\mathrm{Cm}-246$ & $3.58508 \%$ & $0.00000 \%$ \\
\hline $\mathrm{Cm}-247$ & $0.36973 \%$ & $0.00000 \%$ \\
\hline $\mathrm{Cm}-248$ & $0.21040 \%$ & $0.00000 \%$ \\
\hline $\mathrm{Bk}-249$ & $0.00054 \%$ & $0.00000 \%$ \\
\hline $\mathrm{Cf}-249$ & $0.01937 \%$ & $0.00000 \%$ \\
\hline $\mathrm{Cf}-250$ & $0.00261 \%$ & $0.00000 \%$ \\
\hline $\mathrm{Cf}-251$ & $0.00045 \%$ & $0.00000 \%$ \\
\hline $\mathrm{Cf}-252$ & $0.00001 \%$ & $0.00000 \%$ \\
\hline
\end{tabular}

*Note: Values taken from the UOX-18f case, **Note: Values Taken from the UOX-18f-Am case

The $35 \mathrm{v} / \mathrm{o}$ upper limit is established for a transmutation target pin volume identical to that of the driver fuel. However, because the LHGR for the 271 target pins is so low, it is perceivable that the number of target pins could be reduced and the pin diameter increased. Hence, the volume fraction of $\mathrm{MA}-\mathrm{O}_{2}$ in the targets would decrease. Another way that the minor actinide enrichment may be decreased is by artificially increasing the $\mathrm{E}_{\mathrm{MA}}$. The $\mathrm{E}_{\mathrm{MA}}$ may be increased by increasing the transmutation target capture reaction rate (i.e., below the fission threshold). This may be possible by slightly moderating the transmutation target neutron flux to an epithermal energy range below the fission threshold. These options will be the subject of future work. 


\section{Conclusions and Future Work}

The transmutation analysis of the RH-SFR has prompted the establishment of a set of performance criteria with which to equally weigh the merits of various heterogeneous designs. In this preliminary study, the identical assembly design for the driver fuel was adopted for the assembly design of the transmutation targets. By holding the $\mathrm{CR}$ at approximately 0.75 in all cases, and respecting the SNF isotopic vector for the external feed streams, the equilibrium transuranic consumption rate for these heterogeneous designs was kept approximately constant and equal to the homogeneous reference ABR. This allows the adopted transmutation-based performance criteria to evaluate the feasibility of each option. The most economic approach, from the standpoint of a mass balance, is to load the minor actinide mass into the fewest number of targets. This is because less fabrication expenses are incurred for handling radioactive and thermally-hot heavy metal when the number of these specialized target assemblies is reduced. This was the case for the core with six targets. However, it was found that the helium buildup via alpha decay from relatively short lived Cm-242 and Cm-244, created an unacceptable internal pin pressure for the volume of gas plenum available. For this reason, the case for only six targets in the RH-SFR was found to be unfavorable.

Core geometries having 18 target assemblies were thus investigated. Placing the additional 12 target assemblies inside of the active core displaced some of the driver fuel. The reduction in driver assemblies created a significant increase in the power density of the driver fuel. The higher heat generation rate resulted in driver fuel temperatures significantly greater than the core with six targets or the reference ABR. For this reason, the case replacing driver fuel assemblies with transmutation targets in the active core was not considered favorable. Therefore, all of the target assemblies were moved to the reflector region outside of the active core. This alleviated the extra power burden in the driver fuel. However, the lower flux in the reflector diminished the transmutation efficiency of the targets. Hence, a higher minor actinide concentration in the targets was required to respect the SNF isotopic ratio criterion. The resulting increase in minor actinide enrichment caused a slight increase in helium gas pressure. However, the calculated plenum pressure was still within the established criterion of $100 \mathrm{~atm}$. Because this case had the minimum number of targets (maximum feasible MA enrichment) and still met all of the cladding damage, temperature and gas pressure criteria, it is considered feasible.

Next to Cm-242, which is a transmutation product of Am-241, Cm-244 is the second largest producer of helium gas. A fuel cycle was analyzed where curium is separated after each cycle in order to keep Cm-244 out of the fresh transmutation target. Removal of curium reduced the transmutation target plenum gas pressure by $20 \%$. However, because Cm-244 is a transmutation product of Am-243 and its half-life is nearly two decades, it builds up in the fuel cycle faster than it can be depleted. Also, because, $\mathrm{Cm}-244$ decays by alpha emission and has a very short half-life in a geologic time frame, curium is highly radiotoxic. Therefore, if curium is to be separated continuously from the fuel cycle, a long-term storage or disposal solution must be sought.

A heterogeneous core with 48 targets was also analyzed. In this case, the ABR reference core is completely surrounded by target assemblies. When this was done with uranium-based targets, the amount of plutonium breeding in the blanket-like targets resulted in a significant increase in the CR. For this reason, UOX may be an unfavorable transmutation matrix if a large number of targets are used.

When the same core was studied with targets having an $\mathrm{MgO}$ matrix, the $\mathrm{CR}$ remained nearly the same as the ABR reference. For both 48-target cases, the transmutation target met all performance criteria with a large margin. Also, the 48 target cases both had plenum pressures lower than that of the driver fuel. In addition, the $\mathrm{UOX}$ or $\mathrm{MgO}$ matrix had little effect on the minor actinide destruction efficiency of the target. However, the net transuranic burning efficiency of the overall core was reduced due to plutonium breeding in the targets when a large number (48 targets) of UOX-based targets were 
employed. For this reason, $\mathrm{MgO}$ targets are considered feasible even if a large number of targets are specified.

It remains to be determined whether or not the large performance margins achieved in the $\mathrm{MgO}$-based 48 target case is worth the economic penalty of fabricating 2.5 times more targets than the core with 18 targets. Future work will apply additional metrics to quantify the merits related to fuel handling and fabrication. Also of interest is the effect of moderation on the transmutation efficiency of the targets. If a slight moderation is used to increase the transmutation target's flux that exists below the fission threshold, a higher $\mathrm{E}_{\mathrm{MA}}$ is possible. As was seen in the comparison between targets in the active core versus targets in the reflector, an increase in the transmutation efficiency results in a decrease in the minor actinide enrichment, and, therefore, decreases the helium generation. Also, softening the transmutation target flux could reduce the rate of cladding damage, and, hence, allow longer exposure times and higher overall burnups in the targets. Since the LHGR and corresponding centerline temperatures were so low for all cases analyzed here; future studies should provide a comparison analysis between transmutation target assemblies with fewer pins having larger pin diameters. 


\section{References}

1. Ferrer, R., M. Asgari, S. Bays, B. Forget, 2007, "Fast Reactor Alternative Studies: Effects of Transuranic Groupings on Metal and Oxide Sodium Fast Reactor Designs," INL/EXT-07-13236, Idaho National Laboratory.

2. Pillon, S., J. Somers, S. Grandjean, J. Lacquement, 2003, “Aspects of Fabrication of CuriumBased Fuels and Targets," Journal of Nuclear Materials, 320, pp. 36-43.

3. Hoffman, E., W. Yang, R. Hill, 2006, "Preliminary Core Design Studies for the Advanced Burner Reactor Over a Wide Range of Conversion Ratios," ANL-AFCI-177, Argonne National Laboratory.

4. Hamrin, D., 2006, "SCALE: A Modular Code System for Performing Standard Computer Analysis for Licensing Evaluation," ONRNL/TM-2005/39, Oak Ridge National Laboratory.

5. Dubberly, A., K. Yoshida, C. Boardman, T. Wu, 2000, "Super PRISM Oxide and Metal Fuel Core Designs," Proceedings of ICONE8: $8^{\text {th }}$ International Conference on Nuclear Engineering, Baltimore, MD, April, 2-6, 2000.

6. Koch, L. J., "Experimental Reactor - II: An Integrated Experimental Fast Reactor Nuclear Power Station," Argonne National Laboratory.

7. Prunier, C., Y. Guerin, J. Fauger, N. Cocuaud, J. Adnet, 1997, "The Commissariat a L'Energie Atomique SPIN Program: Minor Actinide Fuel and Target Aspects," Nuclear Technology, 120, pp. 110-119.

8. Pillon, S., F. Sudreau, G. Gaillard-Groleas, 2006, "Contribution of PHENIX to the Development of Transmutation Fuels and Targets in Sodium Fast Breeder Reactors," Nuclear Technology, 153, pp. 264-273.

9. Ronchi, C., J. Ottaviani, C. Degueldre, R. Calabrese, 2003, "Thermophysical Properties of Inert Matrix Fuels for Actinide Transmutation," Journal of Nuclear Materials, 320, pp. 54-65.

10. Toppel, B., 1983, "A User's Guide to the REBUS-3 Fuel Cycle Analysis Capability," ANL-83-2, Argonne National Laboratory.

11. Henryson, H., B. Toppel, C. Stenberg, 1976, "MC2-2: A Code to Calculate Fast Neutron Spectra and Multigroup Cross Sections," ANL-8144.

12. Derstine, K., 1984, "DIF3D: A Code to Solve One-, Two-, and Three-Dimensional FiniteDifference Diffusion Theory Problems," ANL-82-64.

13. Carbajo, J., G. Yoder, S. Popov, V. Ivanov, 2001, "A Review of the Thermophysical Properties of MOX and $\mathrm{UO}_{2}$ Fuels," Journal of Nuclear Materials, 299, pp. 181-198.

14. Kim, T. and S. Wang, 2007, "A Metal Fuel Core Concept for 1000 MWt Advanced Burner Reactor,” ANL-AFCI-185, Argonne National Laboratory. 
15. Hofman, G., L. Walters, T. Bauer, 1997, "Metallic Fast Reactor Fuels," Progress in Nuclear Energy, 31, 1-2, pp. 83-110.

16. Pahl, R., C. Lahm, S. Hayes, 1993, "Performance of HT9 Clad Metallic Fuel at High Temperature," 204, pp. 141-147.

17. Lahm, C., J. Koenig, P. Betten, J. Bottcher, W. Lehto, B. Seidel, 1987, "EBR-II Driver Fuel Qualification for Loss-of-Flow and Loss-of-Heat-Sink Tests without SCRAM," Nuclear Engineering and Design, pp. 25-34.

18. Gelles, D., 1994, "Microstructural Development in Reduced Activation Ferritic Alloys Irradiated to $200 \mathrm{dpa}$ at $420{ }^{\circ} \mathrm{C}$," Journal of Nuclear Materials, 212, pp. 714-719.

19. Bauer, T., G. Fenske, J. Kramer, 1987, "Cladding Failure Margins for Metallic Fuel in the Integral Fast Reactor," CONF-870812-232.

20. Walter, A. and A. Reynolds, 1981, "Fast Breeder Reactors", Pergamon Press Inc., Maxwell House, Fairview Park, Elmsford, New York.

21. Wirtz, K., 1978, "Lectures on Fast Reacotrs," American Nuclear Society, La Grange Park, Illinois.

22. Todreas, N. and M. Kazimi, 1990, "Nuclear Systems: Vol. 1, Thermal Hydraulic Fundamentals," Hemisphere, New York.

23. Buiron, L., F. Varaine, D. Lorenzo, H. Palancher, B. Valentin, 2007, "Minor Actinides Transmutation in SFR Depleted Uranium Radial Blanket, Neutronic and Thermal Hydraulic Evaluation," Global 2007: Advanced Nuclear Fuel Cycles and Systems, Boise, ID,

September 9-13, 2007. 